\title{
VALORES EDUCATIVOS, IDEARIO CONSTITUCIONAL Y DERECHO DE LOS PADRES: LA CUESTIÓN DEL «PIN O CENSURA PARENTAL»
}

JOSÉ M. CONTRERAS MAZARÍO 
SUMARIO:

1. INTRODUCCIÓN. 2. DERECHO A LA EDUCACIÓN, LIBERTAD DE ENSEÑANZA E IDEARIO CONSTITUCIONAL. 2.1. Sistema educativo y principios rectores. 2.2. Derecho de los padres a la formación moral y religiosa de sus hijos. 2.3. El menor como titular de los derechos y libertades educativas. 3. SISTEMA EDUCATIVO, CURRÍCULOS EDUCATIVOS Y OBJECIÓN DE CONCIENCIA ESCOLAR. 3.1. Neutralidad escolar. 3.2. Currículos educativos y valores constitucionales. 3.3. Derecho a la objeción de conciencia educativa y «reserva de ley». 4. CONSIDERACIONES FINALES. 


\title{
VALORES EDUCATIVOS, IDEARIO CONSTITUCIONAL Y DERECHO DE LOS PADRES: LA CUESTIÓN DEL «PIN O CENSURA PARENTAL»
}

\author{
JOSÉ M. CONTRERAS MAZARÍO ${ }^{1}$ \\ Catedrático de Derecho Eclesiástico del Estado \\ Universidad Pablo de Olavide
}

«Frente a los numerosos desafíos del porvenir, la educación constituye un instrumento indispensable para que la bumanidad pueda progresar bacia los ideales de paz, libertad y justicia social» Jaques Delors ${ }^{2}$

\section{INTRODUCCIÓN}

Hablar del llamado «pin parental» es abordar una de las cuestiones de mayor actualidad en España, como lo demuestra que el Ministerio de Educación haya presentado una demanda ante el Tribunal Superior de Justicia de Murcia contra la Instrucción por la que se establece. A mi juicio, además de una clara desconfianza hacia la educación pública, en la presente temática confluyen no sólo las dos visiones que sobre educación y enseñanza se han dado a lo largo de nuestra historia ${ }^{3}$ (lo que ya haría relevante la cuestión), sino también las dos posiciones existentes sobre derechos y

1 Catedrático de Derecho Eclesiástico del Estado, Universidad Pablo de Olavide. Dirección postal: Universidad Pablo de Olavide, Carretera de Utrera, Km. 1 (41013-Sevilla). Email: jmconmaz@upo.es

2 DELORS, Jacques: La educación encierra un tesoro, informe UNESCO, 1996, pág. 7.

3 Cfr. DELGADO CRIADO, B., (coord.): Historia de la educación en España y América, Editorial SM, Madrid 1994; PUELLES BENÍTEZ, M.: Educación e ideología en la España contemporánea (17671975), Labor, Barcelona 1980; ID.: Historia de la educación en España, t. II, De las Cortes de Cádiz a l Revolución de 1868, 2a ed., Servicio de Publicaciones del Ministerio de educación y Ciencia, Madrid 1985; VIÑAO FRAGO, A.: Política y educación en los orígenes de la España contemporánea. Examen especial de sus relaciones en la enseñanza secundaria, $1^{a}$ ed., Siglo Veintiuno de España, Madrid 1982. 
libertades fundamentales (esto es, como derechos frente al Estado o como derechos en el Estado) e, incluso, las dos cosmovisiones del Estado y la democracia, como son «la liberal» $\mathrm{y}$ «la socialista».

Un análisis más aproximado a la cuestión permite observar que se utilizan o emplean dos argumentos a favor de este «pin parental», como son, por un lado, el derecho de los padres a elegir la formación moral y religiosa de sus hijos, recogida en el apartado 3, del artículo 27, de la CE y, por otro, la propia libertad (supongo educativa y no tanto de enseñanza). Ello nos obliga a hacer referencia a estas dos realidades, pero también deducir qué se esconde detrás o con de dicha pretensión. Lo que obliga a abordar la temática de nuestro sistema educativo, y en concreto la repercusión que sobre el mismo tiene el apartado 2, del artículo 27, de la CE (apartado 2.1). También será preciso entrar en el análisis del referido derecho de los padres, con especial referencia a su alcance y contenido, todo ello conectado lógicamente con esa pretendida libertad educativa (apartado 2.2), sin olvidar la posición jurídica del menor a estos efectos (apartado 2.3). Deberemos, por tanto, entrar en la relación existente entre los apartados 2 y 3 , del artículo 27 , de la CE, y con ella en la ponderación de ambos preceptos a la hora de ejecutar medidas concretas que se refieran a valores cívicos y morales en el ámbito educativo, y para ello se afrontarán dos cuestiones más como son la incidencia del término «laico» aplicado a la escuela pública (apartado 3.1), la primera, y el tema de los contenidos de los currículos educativos (apartado 3.2), la segunda. Y con ellas se abordarán, finalmente, otras dos temáticas íntimamente relacionadas con las anteriores, a saber: una, la temática de la objeción de conciencia y la segunda la podríamos denominar «reserva de ley» (apartado 3.3). Todo ello nos permitirá deducir un conjunto de consideraciones sobre la constitucionalidad $^{4}$ o no ${ }^{5}$ de una medida como la analizada, así como respecto de los aspectos materiales y formales que la integran.

4 A favor, ver RUIZ ROBLEDO, A.: «Entrevista», Onda Cero, 24/1/2020 (en línea: https://www. ondacero.es/programas/mas-de-uno/audios-podcast/entrevistas/actividadescomplementarias-pin-parent al_202001245e2ab42f0cf2cd32febeb02d.html); TERUEL LOZANO, G; «Pin parental e ideario educativo constitucional: una cuestión abierta al debate democrático», en XVIII Congreso de la Asociación de Constitucionalistas de España, marzo de 2020 (en línea: https://www.acoes.es/congreso-xviii/ponenciasycomunicaciones/).

5 En contra, ver PÉREZ ROYO, J.: «La respuesta constitucional al pin parental», en Eldiario.es, de 20/1/2020 (en línea: https://www.eldiario.es/contracorriente/respuesta-constitucionalveto_ parental_6_986961313.html); SALAZAR BENÍTEZ, O.: «El pin parental y el derecho a la educación», en Eldiario.es, de 18/1/2020 (en línea: https://www.eldiario.es/zonacritica/pin-parentalderechoeducacion_6_985911403.html); VALERO HEREDIA, A.: «El pin parental es inconstitucional», en AlRevésyAlDerecho.es, de 20/1/2020 (en línea: http://blogs.infolibre.es/alrevesyalderecho/?p=5739). 


\section{DERECHO A LA EDUCACIÓN, LIBERTAD DE ENSEÑANZA E IDEARIO CONSTITUCIONAL}

\subsection{Sistema educativo y principios rectores}

1.- Por lo que respecta a la conformación de nuestro sistema educativo, debemos precisar que cuando se analiza el artículo 27 de la CE el debate, tanto político ${ }^{6}$ como $^{2}$ doctrinal $^{7}$, no resulta pacífico ${ }^{8}$. Aunque al final del proceso constituyente se alcanzó un consenso respecto al mismo, no se puede tampoco obviar que éste tema estuvo a punto de hacerlo descarrilar ${ }^{9}$. Para evitarlo el presente precepto, que es uno de los más largos sino el más largo y complejo en materia de derechos humanos, contiene hasta diez apartados en los que de un modo u otro se ven integradas esas dos visiones ${ }^{10}$. En él se hicieron confluir dos posiciones radicalmente distintas y diferenciables en la materia, las cuales pueden reconducirse a una derecha preocupada por conseguir un sistema educativo de gestión privada pero financiado por el Estado, y una izquierda que propuso que el principio protagonista del sistema educativo fueran los centros públicos ${ }^{11}$. Es por ello que el artículo 27 de la CE se encabeza con la mención expresa tanto del derecho a la educación, como de la libertad de enseñanza. En concreto, en su apartado $1^{\circ}$ se dice textualmente: «Todos tienen derecho a la educación. Se reconoce la libertad de enseñanza». Nos encontramos -a nuestro juicio- ante dos derechos o, al menos, ante dos realidades ${ }^{12}$, con contenidos distintos, por más que una parte de la

6 Cfr. GÓMEZ LLORENTE, L.: «De la ciudadanía liberal, a la ciudadanía social», en Temas para el Debate, $\mathrm{n}^{\circ} 149$ (2007), págs. 29-34.

7 Cfr. LERENA ALESÓN, Carlos: Escuelas, ideologías y clases sociales en España, Ariel, Barcelona 1976; MARTÍNEZ LÓPEZ-MUÑIZ, J.L.: «La educación en la Constitución española», en Persona y Derecho, no 6 (1979), págs. 230-273; ORTIZ DIAZ, J.: La libertad de enseñanza; Ed. Universidad de Málaga, Málaga 1980.

8 Cfr. BARNÉS BÁZQUEZ, J.: «La educación en la Constitución de 1978: una reflexión conciliadora», en Revista Española de Derecho Constitucional, núm.12 (1984), págs. 23-27.

9 Cfr. RUBiO LLÓRENTE, F.: «La Política Educativa», en La España de los años setenta, Madrid, 1974, págs. 413-508.

10 Cfr. FERNÁNDEZ-MiRANDA CAMPOAMOR, A., y SÁNCHEZ NAVARRO, A. «Artículo 27: Enseñanza», en ALZAGA, O. (Dir.): Comentarios a la Constitución Española de 1978, Tomo III, EDERSA-Cortes Generales, Madrid 1996, págs. 184 y sigs; GÓMEZ ORFANEL, G.: «Derecho a la educación y libertad de enseñanza», en Revista española de Derecho Constitucional, nº 7 (1983), págs. 410 y sigs.

11 Ver CELADOR ANGÓN, Oscar: «Laicidad constitucional y modelo educativo», en Libertad de conciencia, laicidad y derecho. Liber discipulorum en homenaje al Prof. Dr. Dionisio Llamazares, Ed. Cívitas, Navarra 2014, págs. 281-302; FERNÁNDEZ MIRANDA, A.: De la libertad de enseñanza al Derecho a la educación, CEURA, Madrid 1988.

12 A este respecto, resulta esclarecedor traer a colación cómo explica TORRES DEL MORAL el precepto constitucional, precisando que en el mismo se produce una confusión de conceptos: «se suele denominar libertad de enseñanza a lo que es realmente libertad de educación y derecho a la educación lo que es derecho a la enseñanza o a la instrucción» (cit. en TORRES DEL MORAL, Antonio: Principios de Derecho Constitucional español, vol. I, Atomo, Madrid 1985, pág. 340). 
doctrina quiera ver un solo derecho fundamental ${ }^{13}$. $\mathrm{Y}$ a pesar igualmente de que nuestro TC considere que el diferenciar entre enseñanza y educación responde más bien a modelos teóricos, toda vez que ambas expresiones responden a una misma realidad $^{14}$.

Partiendo de lo dicho, puede afirmarse que la educación tiene un carácter intrínsecamente abierto, y aunque es difícil definirlo académicamente, puede señalarse que procede de la palabra latina ducere (conducir, guiar) ${ }^{15}$. A estos efectos, puede definirse la educación como "aquel proceso mediante el cual los individuos adquieren y manifiestan conocimientos, sentimientos y actitudes sobre la vida social a través de la acción predominantemente formalizada de otros individuos, grupos e instituciones, realizada mediata e inmediatamente a partir de determinados idearios o tradiciones de pensamiento» ${ }^{16}$. El derecho a la educación supone, por tanto, el reconocimiento de la libertad del individuo para acceder a las ofertas culturales de conocimientos existentes y desarrollarse como persona, perfeccionar sus capacidades de comunicar y de comunicarse con los demás ${ }^{17}$. Mientras que, por su parte, la libertad de enseñanza supone el reconocimiento de una esfera de libertad en la que se garantice la transmisión de todos aquellos conocimien-

13 En este sentido, ver ALÁEZ CORRAL, B.: «El ideario educativo constitucional como fundamento de la exclusión de la educación diferenciada por razón de sexo de la financiación pública», en Revista Española de Derecho Constitucional, no 86 (2009), págs. 34-35.

14 Entre las sentencias más destacadas están las siguientes: TC: sentencias 5/1981, de 13 de febrero (recurso LOECE); 77/1985, de 27 de junio (recurso LODE); 86/1985, de 10 de julio (subvenciones a centros docentes privados); 26/1987, de 27 de enero (recurso del Gobierno vasco contra la LRU); 188/2001, de 20 de septiembre (recurso Cataluña contra Orden que regula las becas a estudiantes); 133/2010, de 2 de diciembre (sobre la escolarización obligatoria y el «homeschooling»); 184/2012, de 17 de octubre (recuso LOCE); 212/2012, de 14 de noviembre (recurso LOCE); 213/2012, de 14 de noviembre (recurso LOCE); 214/2012, de 14 de noviembre (recurso LOCE); 6/2013, de 17 de enero (recurso LOCE); 131/2013, de 5 de junio (recurso LOU); 134/2013, de 6 de junio (recurso LOU); 141/2013, de 11 de julio (recurso LOU); 158/2013, de 26 de septiembre (recurso LOU); 159/2013, de 26 de septiembre (recurso LOU); 160/2013, de 26 de septiembre (recurso LOU) 14/2018, de 20 de febrero (recurso LOMCE); 31/2018, de 10 de abril (recurso LOMCE); 49/2018, de 10 de mayo (recurso LOMCE); 53/2018, de 24 de mayo (recurso LOMCE); 66/2018, de 21 de junio (recurso LOMCE); 67/2018, de 21 de junio (recurso LOMCE), y 68/2018, de 21 de junio (recurso LOMCE). Cfr. MARTIN SÁNCHEZ, I.: «La libertad de enseñanza en la jurisprudencia del Tribunal Constitucional español», en Anuario de Derecho eclesiástico, vol. 2 (1986), págs. 193-238.

También para el TEDH, en este caso, el art. 2 del protocolo I al CEDH consagra sólo un derecho: TEDH, sentencias de 23 de julio de 1968, caso relativo a algunas cuestiones sobre el régimen lingüístico belga, n. 3, y de 7 de diciembre de 1976, caso Kjeldsen, Busk Madsen y Pedersen, n. 50.

15 Por educación cabe entender «la pretensión de toda persona a adquirir, según sus aptitudes, la cultura y la instrucción en igualdad de condiciones, de una diversidad de organismos que impartan la enseñanza y den igualdad de oportunidades para acceder a ellos» (BURDEAU, C.: Les libertes publiques, Librairie générale de Droit et Jurisprudence, París 1972, pág. 315).

16 CÁMARA VILLAR, G.: «Educación política, libertad y sistema de enseñanza en España: problemas y posibilidades (I)», en Revista de la Facultad de Derecho de la Universidad de Granada, núm. 2 (1983), págs. 114-130.

17 GARCÍA- GUTIÉRREZ, J.: «La dimensión cultural del derecho a la educación y su expansión a través del ideario de los centros docentes», en Revista española de pedagogía, nº 67 (2009), págs. 529-544. 
tos que permitan situar a la persona en condiciones de afrontar su futuro ${ }^{18}$. La enseñanza supone, pues, «un proceso de aprendizaje programado y generalmente institucionalizado que sirve, las más de las veces, para integrar un individuo en la sociedad, en una comunidado en otro grupo anejo» ${ }^{19}$. La libertad de enseñanza se configura entonces como un elemento instrumental de la investigación científica y la docencia, y no propiamente en un instrumento de difusión de la ideología, las convicciones o las creencias, aunque no puede obviarse que en toda labor docente existe siempre cierta transmisión de valores ${ }^{20}$.

2.- Junto a lo expuesto, debemos traer a colación asimismo el derecho de libertad de conciencia y religiosa, garantizado en el artículo 16 de la CE, el cual se proyecta sobre los derechos de educación y de enseñanza como causa fundante, o -como lo ha señalado el propio TC- éstas se convierten en «proyeccion[es] de la libertad ideológica y religiosa y del derecho a expresar y difundir libremente los pensamientos, ideas u opiniones» $(\mathrm{STC} 5 / 1981, \mathrm{FJ} 7)^{21}$. La educación en general se convierte de esa manera en un elemento esencial para la consecución de otro objetivo esencial como es la libre formación de la conciencia, sin la cual no hay plenamente libertad. Ahora bien, la consecución de la libre formación de la conciencia obliga a un sistema de pluralidad ideológica en tanto que valor superior del ordenamiento (art. 1.1 CE), que en el campo educativo supone una pluralidad de centros y una pluralidad en los centros ${ }^{22}$. Esta pluralidad de tipos educativos o de escuelas ha supuesto, en el caso de España, la existencia de

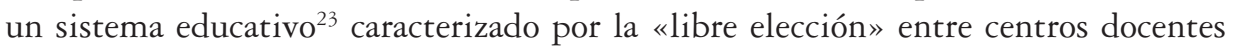

18 En este sentido, el TC — en su sentencia 5/1981- ha considerado que «la libertad de enseñanza es una actividad encaminada de modo sistemático y con un mínimo de continuidad a la transmisión de un determinado cuerpo de conocimiento y valores» (FJ 7).

19 HENGSBACH, F.: «Libertad de enseñanza y derecho a la educación (el Estado democrático y la educación)», en Persona y Derecho, vol. 6 (1979), págs. 85-86.

20 A este respecto, ver TEDH: sentencias de 7 de diciembre de 1976, caso Kjeldsen, Busk Madsen y Pedersen c. Dinamarca, y de 25 de febrero de 1982, asunto Campbell y Cosans c. Reino Unido.

${ }^{21}$ Cfr. PELAYO OLMEDO, J.D.: «Reflexiones sobre la relación entre Derecho a la Educación y la libertad de pensamiento, conciencia y religión», en Laicidad y Libertades. Escritos Jurídicos, vol. 13 (2013), págs. 265-295.

22 A este respecto, el TC ha manifestado que «(...) el derecho a la educación se ha de realizar dentro de un sistema educativo plural, regido por la libertad», por lo que su reconocimiento «implica la inexistencia de un monopolio estatal docente $y$, en sentido positivo, la existencia de un pluralismo educativo institucionalizado" (STC 5/1981). Cfr. LARICCIA, S.: «La attuazione dei principi costituzionali in materia religiosa», en Il Diritto ecclesiastico, vol. 52, fasc. I, parte I (1981), p. 3-12.

23 La legislación orgánica desarrollada desde la aprobación de la CE en materia de educación y enseñanza ha sido la siguiente: Ley Orgánica 5/1980, de 19 de julio, por la que se reguló el Estatuto de Centros Escolares (en adelante, LOECE); Ley Orgánica 8/1985, de 3 de julio, reguladora del Derecho a la Educación (en adelante, LODE); Ley Orgánica 1/1990, de 3 de octubre, de Ordenación General del Sistema Educativo (en adelante, LOGSE); Ley Orgánica 9/1995, de 20 de noviembre, de la Participación, la Evaluación y el Gobierno de los Centros Docentes (en adelante, LOPEGCD); Ley Orgánica 2/2006, de 3 de mayo, de Educación (en adelante, LOE) y Ley Orgánica 8/2013, de 9 de diciembre, para la Mejora de la Calidad Educativa (en adelante, LOMCE). 
públicos y centros docentes privados ${ }^{24}$, diferenciando dentro de los segundos entre la llamada escuela concertad ${ }^{25}$ y la estrictamente escuela privada ${ }^{26}$, esto es, en diferencia con la concertada aquélla que no recibe dinero público ${ }^{27}$, pero también el rechazo de la modalidad del «homo schools» o escuelas en casa ${ }^{28}$.

\subsection{Derecho de los padres a la formación moral y religiosa de sus bijos (art. 27.3 CE)}

Una breve aproximación a los distintos textos internacionales en la materia pone de manifiesto como la presente cuestión aparece vinculada ${ }^{29}:$ i) bien con el contenido del derecho a la libertad de pensamiento, de conciencia y de religión (lo que sucede en los arts. 18 del PIDCP, 5 de la Declaración de 1981, 4 de la Convención sobre los Refugiados, ó 4 de la Convención sobre los Apátridas), o ii) bien con el contenido del derecho a la educación (así se plasma en los arts. 26 DUDH, 13 PIDESC, 2 Protocolo Adicional $1^{\circ}$ al CEDH, 5 de la Convención de la UNESCO, ó 28 y 29 de la Convención sobre los Derechos del Niño). Aunque a primera vista pudiera parecer que su ubicación en uno u otro de los derechos resulta inocua, no es así, ya que la misma tiene repercusiones jurídicas relevantes por lo que se refiere al ámbito de su tutela y garantía. Baste en este momento con poner de manifiesto que dichos términos deben entenderse en el contexto del derecho a la educación en sus dos manifestaciones, a saber: i) como libertad de aprender, o de optar porque el hijo reciba una determinada enseñanza; y/o ii) como libertad de enseñar, que — como establece el PDESC encuentra sus límites en la consecución del «pleno desarrollo de la personalidad bumana $y$ en el respeto a los derechos y libertades fundamentales» (art. 13.1) $)^{30}$, así como en el hecho de que la misma «se ajuste a las normas mínimas que prescriba el Estado» (art. 13.3).

Es, por tanto, esta temática -esto es, la relativa a la pluralidad de centros-, la que debe ponerse en relación directa con el reseñado derecho de los padres a que sus hijos

24 LOE: art 108.4: «La prestación del servicio público de la educación se realizará, a través de los centros públicos y privados concertados».

25 LODE: Título IV.- De los centros concertados: arts. 50 a 63, y LOE: Capítulo III.- Centros privados: arts. 114 y 115, y Capítulo IV.- Centros privados concertados: arts. 116 y 117.

26 Ver LODE: arts. 25 y 26; LOE: arts. 108 y 109; y LOMCE: art 116.

27 Ver LODE: arts. 25 y 26; LOE: arts. 108 y 109; y LOMCE: art 116.

28 TC: sentencias 260/1994 y 133/2010. Cfr. ASENSIO SÁNCHEZ, M.A.: «La objeción de conciencia al sistema escolar: la denominada educación en casa», en Laicidad y libertades. Escritos jurídicos, $\mathrm{n}^{\circ} 6$ (2006), págs. 9-46; ID.: «La educación en casa o homeschooling en la doctrina del Tribunal Constitucional», en Foro. Nueva Época, nº 15 (2012), págs. 185-212.

29 Cfr. FERNANDEZ-CORONADO, A., y PELAYO OLMEDO, J.D.: «Integrar la diversidad religiosa en la educación: preservar las convicciones personales y formar en derechos humanos y valores democráticos: propuestas de la comunidad internacional para un entorno educativo integral», en FERNÁNDEZ-CORONADO, A. (coordra.): Integrados. Claves jurídicas: derecho a la educación, diversidad religiosa y cobesión social, Ministerio de Justicia, Madrid 2019, págs. 16-20.

30 Cfr. NUEVO LÓPEZ, P.: «Derechos fundamentales e ideario educativo constitucional», en Revista de Derecho Político, núm. 89 (2014), págs. 205-238. 
reciban una formación religiosa o moral conforme con las propias convicciones establecido en el apartado 3, del artículo 27, de la CE, y que supone básicamente el derecho a una libre elección de centro por parte del titular o quien ejerza su custodia, de modo que se garantice a la persona el derecho a optar por el tipo de centro escolar que más concuerde con sus ideas, creencias o convicciones ${ }^{31}$, para lo cual es necesario - a su vez- el derecho a crear centros docentes privados (art. 27.6 CE) ${ }^{32}$, sin que de ello pueda deducirse la obligación para el Estado de ofertar sistemas educativos «a la carta», ni para el particular el derecho a reclamarlos ${ }^{33}$. Por consiguiente, cabe señalar que la facultad de opción que corresponde a los padres respecto a una educación religiosa y moral acorde con sus propias convicciones ha sido interpretada mayoritariamente en el ámbito internacional como la obligación de permitir la existencia de centros docentes no estatales y la posibilidad por parte de las personas físicas o jurídicas de crear tales establecimientos, así como el derecho de dirigirlos. Todo ello entendido como elemento indispensable para la construcción de una sociedad democrática y pluralista ${ }^{34}$.

Tampoco cabe entender que de este derecho así entendido pueda deducirse el establecimiento de un único y completo sistema educativo ${ }^{35}$, ni un derecho ni un deber dirigido a integrar dentro de los sistemas educativos nacionales una enseñanza o adoctrinamiento en una religión o creencias determinadas. A este respecto, resulta de sumo interés la posición mantenida por el Comité de Derechos Humanos de las

31 En contra, ver STC 5/1981, quien manifestó que «el derecho de los padres a decidir la formación religiosa y moral que sus hijos han de recibir, consagrado por el art. 27.3 de la Constitución, es distinto del derecho a elegir centro docente que enuncia el art. 13.3 del Pacto Internacional de Derechos Económicos, Sociales y Culturales, aunque también es obvio que la elección de centro docente sea un modo de elegir una determinada formación religiosa y moral» (FJ 8). Es más, esta afirmación ha llevado al TC a conectar de forma directa el derecho garantizado en el punto 3, del art 27, de la CE con el derecho a la enseñanza de la religión garantizado en el punto 3, del art 2, de la LOLR. A nuestro juicio, dicha conexión no resulta tan clara y resulta contraria a lo manifestado por el Comité de Derechos Humanos en su Comentario núm. 22 al artículo18 del PIDCP: «el párrafo 4 del artículo 18 permite que en la escuela pública se imparta enseñanza de materias tales como la historia general de las religiones y la ética siempre que ello se haga de manera neutral y objetiva. La libertad de los padres o de los tutores legales de garantizar que los hijos reciban una educación religiosa y moral que esté de acuerdo con sus propias convicciones proclamada en el párrafo 4 del artículo 18 está relacionada con la garantía de la libertad de enseñar una religión o creencias que se recoge en el párrafo 1 del mismo artículo $18 »$. El Comité señala además que «la educación obligatoria que incluya el adoctrinamiento en una religión o unas creencias particulares es incompatible con el párrafo 4 del artículo 18, a menos que se hayan previsto exenciones y posibilidades que estén de acuerdo con los deseos de los padres o tutores» (punto 6).

32 Este es también el sentido otorgado por el TEDH al art. 2 del PA1CEDH, para quien «la obligación que nace para los Estado es hacer posible que todas las personas sometidas a su jurisdicción se beneficien y tengan acceso al sistema educativo que exista en cada momento" (STEDH de 23 de julio de 1968, caso Relativo a ciertos aspectos del régimen lingüístico en Bélgica).

33 Cfr. SSTC 260/1994 y 133/2010. A este respecto, vid. CELADOR ANGÓN, O., "El modelo de educación diferenciada en la reciente doctrina constitucional", en Derechos y libertades, núm. 42 (2020), págs. 27-60.

34 Cfr. CONTRERAS MAZARÍO, J. Mª «La enseñanza religiosa en Derecho internacional y comparado», en Bandue, no 1 (2007), págs. 47-82.

35 Cfr. STS de 31 de enero de 1997, párr. 5. 
Naciones Unidas, en su comentario núm. 22 al artículo 18 del PIDCP ${ }^{36}$, para quien esta libertad (de los padres o tutores de garantizar que sus hijos o pupilos reciban una educación religiosa y moral acorde con sus convicciones) está relacionada con la garantía de la libertad de enseñar una religión o creencias del párrafo $1 .^{\circ}$ del mismo artículo 18 y permite que en la escuela pública se imparta enseñanza de materias tales como la historia general de las religiones y la ética, siempre que ello se haga de manera neutral y objetiva. Pero añade que la educación obligatoria que incluya el adoctrinamiento en una religión o unas creencias particulares es incompatible con el contenido del citado artículo 18, a menos que se hayan previsto exenciones y posibilidades que estén de acuerdo con los deseos de los padres o tutores ${ }^{37}$.

Es aquí donde debe situarse el referido derecho de los padres y no — como muchas veces se hace de manera interesada- en un derecho a recibir enseñanza confesional de una religión determinada. Amén del derecho reconocido a éstos de participar en el control y gestión de todos los centros sostenidos por la Administración con fondos públicos (art. 27.7 CE) ${ }^{38}$. En definitiva, la normativa internacional garantiza el respeto al derecho de los padres a asegurar esa formación religiosa y moral, pero no la obligación a los Estados a imponerla. No hay, entonces, obligación para los Estados ni, por ende, para sus respectivos sistemas educativos, sino que tales cuestiones quedan derivadas a la libre elección de cada uno de ellos. Nos encontramos, por tanto, ante un derecho-libertad conectado con la libertad de pensamiento, conciencia y religión, que no constituye - sin embargo- un contenido propio y esencial del derecho a la educación, sino que afecta a creencias religiosas o valoraciones morales específicas de los ciudadanos que, aunque pueden ser compatibles con el contenido esencial del derecho fundamental a la educación, no están comprendidos necesariamente en el mismo ${ }^{39}$.

36 Consultar en internet: http://hrlibrary.umn.edu/hrcommittee/Sgencom22.html (visitado el 28-5-2019).

37 El citado Comité ha manifestado que «el párrafo 4 del artículo 18 permite que en la escuela pública se imparta enseñanza de materias tales como la bistoria general de las religiones y la ética siempre que ello se haga de manera neutral y objetiva. La libertad de los padres o de los tutores legales de garantizar que los hijos reciban una educación religiosa y moral que esté de acuerdo con sus propias convicciones proclamada en el párrafo 4 del artículo 18 está relacionada con la garantía de la libertad de enseñar una religión o creencias que se recoge en el párrafo 1 del mismo artículo 18». El Comité señala además que «la educación obligatoria que incluya el adoctrinamiento en una religión o unas creencias particulares es incompatible con el párrafo 4 del artículo 18, a menos que se hayan previsto exenciones y posibilidades que estén de acuerdo con los deseos de los padres o tutores» (punto 6)

38 Cfr. MARTÍN RETORTILLO, L.: «Los padres tendrán derecho preferente a escoger el tipo de educación que habrá de darse a sus hijos», en Anuario de Derecho Eclesiástico del Estado, vol. XXIV (2008), págs. 223-290.

39 Cfr. SUÁREZ PERTIERRA, G.: «La enseñanza de la religión en el sistema educativo español», en Laicidad y Libertades. Escritos Jurídicos, vol. 4 (2004), págs. 225-247. 


\subsection{El menor como titular de los derechos y libertades educativas}

Una tercera cuestión tiene que ver con los titulares de estos derechos, y en particular la posición que al efecto se reconoce, por un lado, a los alumnos y, por otro, a los padres y tutores, en tanto que sujetos activos de los presentes derechos. Pues bien, en la mayoría de las ocasiones éstos están referidos a los padres, o en su caso a los tutores o representantes legales, y sólo en contadas ocasiones —aunque especialmente relevantes- la titularidad del derecho se atribuye al alumno, al niño o al menor como son los casos de los artículos 28 y 29 de la CDN, o el artículo 5 de la Declaración de las Naciones Unidas, de 1981, relativa a todas las formas de Intolerancia y Discriminación fundadas en la religión o las convicciones.

El presente dato ha llevado a afirmar que, respecto del niño o menor, el derecho a la educación se constituye en un derecho complejo, ya que los menores resultan a la vez titulares y beneficiarios, siendo entonces los Estados los obligados a asegurar su plena y efectiva realización y los padres los llamados a escoger las modalidades de su ejercicio, con el fin de que los niños puedan ir conformando su conciencia en un contexto educativo sin condicionamientos morales o religiosos, al tiempo que deberán de respetar, asimismo, el interés general superior del derecho a la educación de los mismos (cfr. art. $18 \mathrm{CDN}$ ). En esta línea, el TEDH ha manifestado que «el derecho a determinar el modo de educación de los hijos es una parte integrante del derecho de custodia», con el único límite del interés superior del menor ${ }^{40}$. Y este límite es tan importante que el propio Tribunal europeo, en su sentencia Olsson (de 24 de mayo de 1988), ha destacado que, en los supuestos de adopción o de acogida, el derecho de elección de los padres estará condicionado por la formación religiosa o filosófica que haya dirigido hasta ese momento la formación del menor (arts. 20.3 CDN y 5.4 Declaración $1981)^{41}$.

Partiendo de la primera de las consideraciones, entendemos que los derechos educativos atribuidos a los padres nacen del instituto de la representación legal (art. 162 CC), así como del derecho-deber de asistencia y tutela que tienen para sus hijos

40 Cfr. Cillero BRUÑOL, M.: «El interés superior del niño en el marco de la Convención Internacional sobre los Derechos del niño», en Justicia y Derechos del Niño, no 1 (1999), págs. 45-62; RAVETLLAT, I.: «El interés superior del niño: concepto y delimitación del término», en Educatio Siglo $X X I$, vol. 30, n. 2 (2012), págs. 92-105; ROCHA: «La persona del menor, su interés superior, su autonomía y el libre desarrollo de su personalidad», en Actualidad Jurídica Iberoamericana, n. 2 (2015); RODRIGO LARA, $\mathrm{M}^{\mathrm{a}}$ B.: «El menor de edad y su derecho de libertad religiosa como agentes determinantes del interés superior del niño», en Anuario de Derecho Eclesiástico del Estado, vol. XXXV (2019), págs. 351-362.

${ }^{41}$ Cfr. ASENSIO SÁNCHEZ, M.A.: La patria potestad y la libertad de conciencia del menor. El interés del menor a la libre formación de su conciencia, Tecnos, Madrid 2006; PÉREZ ÁLVAREZ, S. (2016): «El derecho del menor a ser educado conforme a su propia conciencia según los estándares del Tribunal Europeo de los Derechos Humanos», en Revista de Derecho Político, vol. 95 (2016), págs. 147-188. 
menores y pupilos (art. $154 \mathrm{CC})^{42}$. Por consiguiente, se trata de derechos cuyos sujetos activos los son los hijos y pupilos en tanto que personas físicas (art. $30 \mathrm{CC}$ ), pero que los padres y tutores ejercen mediante una representación implícita. No obstante, y por lo que respecta al derecho a elegir la formación religiosa y moral que esté de acuerdo con las propias convicciones (art. 27.3 CE), debe precisarse que el mismo se atribuye de manera directa a los padres sin que en ningún momento se haga referencia a la figura del menor, salvo la importante referencia que en este sentido ha hecho el artículo 24 de la CDFUE. Dicho derecho implica para los padres la facultad de decidir sobre la educación y, por consiguiente, también sobre la formación escolar de sus hijos, pero sin que ello pueda suponer un menoscabo de la propia esencia del derecho a la educación, en tanto que los padres no son "propietarios" de sus hijos ni de la conciencia de sus hijos (art. 13.1 PIDESC). A estos efectos, conviene asimismo precisar que no debe confundirse la cooperación de los padres en el funcionamiento y gestión de las escuelas (art. 27.6 CE) con el derecho que los mismos tienen reconocido respecto a la formación religiosa y moral de sus hijos ${ }^{43}$.

Todo ello supondría una transformación de la naturaleza del derecho, de modo que más que un derecho subjetivo se trataría de un derecho objetivo del que dimana una responsabilidad a cargo de las personas a quienes incumbe el ejercicio de esa función, y cuyo contenido presenta la doble vertiente del cuidado de la persona y el de los bienes, en cuanto aspecto interno y externo de la patria potestad, que se traduce en una doble función: educadora y sustitutiva, en orden a los aspectos personales y patrimoniales que la patria potestad comporta. No obstante, y aunque la función educativa, en la que se inserta el derecho constitucional del artículo 27.3, se asienta en el principio de discrecionalidad de los titulares de la potestas, la conflictividad entre función educativa de los padres y libertad de conciencia del menor sólo puede ser resuelta a la luz del libre desarrollo de la personalidad y de la dignidad humana; y, consiguientemente, a favor del interés superior del menor (arts. 14.2 CDN, 5.2 Declaración 1981, 24.2 CDFUE y 2 LOPM).

42 Cfr. ASENSIO SÁNCHEZ, M.A.: Minoría de edad y libertad religiosa en el ordenamiento jurídico español, Tirant lo Blanch, Valencia 2018; MORENO ANTÓN, M.: Multiculturalidad y libertad religiosa del menor de edad, Fundación Universitaria Española, Madrid 2007; PUENTE ALCUBILLA, V.: Minoría de edad, religión y Derecho, Ministerio de Trabajo, Madrid 2001; VALERO, A: La libertad de conciencia del menor de edad desde una perspectiva constitucional, Centro de Estudios Políticos y Constitucionales, Madrid 2009.

43 Cfr. ARECES PIÑOL, $\mathrm{M}^{\mathrm{a}}$ T.: «Tutela del menor y libertad religiosa», en Estudios Jurídicos. En homenaje al profesor Vidal Guitarte I, Castellón-Valencia 1999, págs. 31 y sigs.; LÓPEZ ALARCÓN, M.: «Nuevo derecho de menores y ejercicio de opciones religiosas», en Anales de Derecho. Revista de la Facultad de Derecho. Universidad de Murcia, núm. 15 (1997), págs. 327 y sigs.; MORENO ANTÓN, M.: «Minoría de edad y libertad religiosa: estudio jurisprudencial», en Revista general de Derecho Canónico y de Derecho Eclesiástico del Estado, no 19 (2019); PÉREZ ÁLVAREZ, S., El derecho del menor a ser educado conforme a su propia conciencia en la era digital, Dykinson, Madrid, 2021. RODRIGO LARA, M.B.: Minoría de edady libertad de conciencia, Madrid 2005; ROSELL, J.: «El derecho de libertad religiosa del menor en las Leyes de libertad religiosa española, italiana y portuguesa», en Derecho de familia y libertad de conciencia en los países de la Unión Europea y el Derecho comparado. Actas del IX Congreso Internacional de Derecho Eclesiástico del Estado, San Sebastián, 1 a 3 de junio de 2000, págs. 787-801. 


\section{SISTEMA EDUCATIVO, CURRÍCULOS EDUCATIVOS Y OBJECIÓN DE CONCIENCIA ESCOLAR}

En el caso concreto de Murcia, la cuestión se plantea tanto desde el plano material como formal. Desde una perspectiva material, las instrucciones murcianas establecen, respecto de aquellas «actividades complementarias» que sean impartidas «por personas ajenas al claustro del centro educativo», la obligación de que los centros educativos informen a los padres para que los mismos "puedan manifestar su conformidad o disconformidad con la participación de sus hijos menores en dichas actividades» ${ }^{44}$. A este respecto, cabe señalar que las llamadas «asignaturas complementarias» no son materias extraescolares, toda vez que las mismas forman parte del proyecto educativo del centro lo que impide que las mismas queden a la libre discrecionalidad de los padres o a su previa autorización ${ }^{45}$. Así, pues, con la cuestión del llamado "pin parental» se está hablando, por un lado, de neutralidad del Estado y, por otra, de la transmisión de unos valores constitucionales (libertad, igualdad y no discriminación y pluralismo), lo que obliga a una interpretación equilibrada de ambos conceptos, de forma que los haga compatibles entre sí. A tal fin, debe acotarse lo que se entiende por neutralidad escolar y establecer hasta dónde llega la necesidad de transmitir los valores constitucionales que deberían impregnar la labor educativa, facilitando de este modo el libre desarrollo de la personalidad. Amén de la cuestión formal del tipo de norma: interpositio legislatoris.

\subsection{Neutralidad escolar}

\subsubsection{No adoctrinamiento ideológico}

Que el Estado sea laico ${ }^{46} \mathrm{y}$, por lo tanto, neutral respecto a las distintas formulaciones en las que se concretan las corrientes ideológicas y religiosas existentes en la sociedad no significa que no disponga de unos valores de los que fluyen las normas y que constituyen la moral pública, sobre las que el Estado no puede mostrarse neutral

44 Resolución de 29 de agosto de 2019, de la Secretaria General de la Consejería de Educación y Cultura por la que se dictan instrucciones de comienzo del curso 2020-2021, para los centros docentes que imparten Educación Infantil y Primaria: 15. Actividades programas por los centros; y Resolución de 29 de agosto de 2019, de la Secretaría General de la Consejería de Educación y Cultura, por la que se dictan instrucciones de comienzo del curso 2019-2020 para los centros docentes que imparten Educación Secundaria Obligatoria y Bachillerato: 25. Actividades programadas por los centros.

45 En contra, ver TERUEL LOZANO, G.M.: «Pin Parental e ideario educativo-constitucional: una cuestión abierta al debate democrático», en internet: https:/www.acoes.es/congreso-xviii/ wp-content/uploads/sites/4/2020/02/Mesa_1_Germ\%C3\%A1n-Teruel-Lozano_Pin-Parental-e-idearioeducativo-constitucional.-Una-cuesti\%C3\%B3n-abierta-al-debate-democr\%C3\%A1tico.pdf

46 STC 46/2001, de 15 de febrero, FJ 4. Ver también TC: sentencias 154/2002, de 18 de julio; 101/2004, de 2 de junio; 38/2007, de 15 de febrero, FJ 5, y 128/2007, de 4 de junio, FFJJ 9 y 10. 
«So pena de traicionarse así mismo» ${ }^{47}$. El propio TC ha señalado a este respecto que «a la finalidad de la educación se le asigna por el texto constitucional un contenido que bien merece la calificación de moral, entendida esta noción en un sentido cívico y aconfesional: pleno desarrollo de la personalidad bumana en el respeto a los principios democráticos de convivencia $y$ a los derechos y libertades fundamentales» ${ }^{48}$.

Por lo que respecta a la neutralidad escolar, cabe precisar que el citado precepto constitucional, es decir, el artículo 27.3 de la CE, se ha proyectado sobre el segundo de los contenidos reseñados, esto es, sobre la pluralidad en la escuela, lo cual tiene una especial incidencia sobre el término «laico» aplicado a las escuelas públicas. Pues bien, a este respecto lo primero que cabe señalar es que dicha pluralidad supone que se establezca como principio informador interno de los centros docentes públicos la neutralidad escolar. Una neutralidad que fue ya concretada, en 1976, por el TEDH ${ }^{49}$, al considerar que con el conjunto del CEDH «se probíbe al Estado perseguir una finalidad de adoctrinamiento que pueda ser considerada como no respetuosa de las convicciones religiosas y filosóficas de los padres. Aquí se encuentra el límite que no debe ser sobrepasado. Tal interpretación se concilia a la vez con la primera frase del artículo 2 del Protocolo, con los artículos 8 a 10 del Convenio y con el espíritu general de éste, destinado a proteger y promover los valores de una sociedad democrática» (FJ 53 in fine). En el caso en cuestión, el Tribunal de Estrasburgo concluyó que «el examen de la legislación impugnada prueba, en efecto, que no constituye un intento de adoctrinamiento tendente a preconizar un comportamiento sexual determinado. Esta legislación no se consagra a exaltar el sexo ni a incitar a los alumnos a dedicarse precozmente a prácticas peligrosas para su equilibrio, su salud o su futuro, o reprensibles para muchos padres. Además, la legislación no afecta al derecho de los padres de aclarar y aconsejar a sus bijos, de ejercitar con ellos sus naturales funciones de educadores o de orientarles en una dirección, conforme a sus propias convicciones religiosas o filosóficas» (FJ 54) ${ }^{50}$.

En este mismo sentido se pronunció el TC, en su sentencia 5/1981, al señalar que «esta neutralidad (...) es una característica necesaria de cada uno de los puestos docentes integrados en el centro, y no el bipotético resultado de la casual coincidencia en el mismo centro y frente a los mismos alumnos, de profesores de distinta orientación ideológica cuyas enseñanzas se neutralicen recíprocamente» (FJ 9). Precisando seguidamente que «la neutralidad ideológica de la enseñanza en los centros escolares públicos (...) impone a los docentes que en ellos desempeñan su función una obligación de renuncia a cualquier forma de adoctrinamiento ideológico, que es la única actitud compatible con el respeto a la libertad de las familias que, por

47 LLAMAZARES FERNÁNDEZ, D.: «Educación para la ciudadanía, laicidad y enseñanza de la religión», en Laicidad y Libertades. Escritos jurídicos, vol. 6 (2006), pág. 255.

48 STS 565/1197, FJ 2, y reiterado en las SSTS 2401/1998, FJ 4, y 8317/1998, FJ 4.

49 STEDH de 7 de diciembre de 1976, caso Kjeldsen, Busk Madsen y Pedersen c. Dinamarca.

50 En contra, ver Voto particular del juez Verdross, para quien: «(...) no puede desconocerse que la instrucción en una escuela privada, incluso subvencionada por el Estado, y la enseñanza en el propio domicilio causan siempre sacrificios materiales a los padres. Si, por tanto, los demandantes no tenían la facultad de hacer dispensar a sus hijos de asistir a los cursos en cuestión, existiría en su perjuicio una discriminación no justificada probibida por el artículo 14 del Convenio, en comparación con los padres cuyas convicciones religiosas y morales son conformes con las del legislador danés». 
decisión libre o forzadas por las circunstancias, no han elegido para sus hijos centros docentes con una orientación ideológicamente determinada y explícita» (ibid $)^{51}$.

De esta forma, puede afirmarse que la «neutralidad» educativa de los centros públicos supone la inexistencia de una ciencia o doctrina oficiales ${ }^{52}$, salvo lo que se deduzca materialmente de las finalidades impuestas constitucionalmente a la educación por el artículo 27.2, esto es, promover el pleno desarrollo de la personalidad en el respeto a los principios democráticos de convivencia y a los derechos y libertades fundamentales, y que afecta directamente a la liberta de cátedra.

\subsubsection{Libertad de cátedra y neutralidad escolar}

A estos efectos, el derecho a la libertad de cátedra se ha definido como «el derecho de quienes llevan a cabo la función de enseñar a desarrollarla con libertad. Esto es la facultad que tiene todo docente de transmitir en su actividad docente sus conocimientos como considere oportuno, de modo que pueda expresar sus ideas y convicciones científicas y artísticas y de elegir el planteamiento teórico y el método, sin más limites que los establecidos en la Constitución o en las leyes y los derivados de la organización de las enseñanzas. La libertad de cátedra, intimamente relacionada con la libertad de enseñanza, es una proyección de la libertad ideológica y supone el derecho a difundir libremente los pensamientos, ideas u opiniones de los docentes» (Auto TC 42/1992) ${ }^{53}$. La libertad de cátedra está establecida, por tanto, para impedir que los poderes públicos o los particulares puedan obstaculizar a los docentes en la investigación y la transmisión de la verdad ${ }^{54}$. Se trata, por tanto, de un derecho

51 El TS ha reconocido que «cuando la educación pública se proyecte sobre la explicación del pluralismo de la sociedad en sus diferentes manifestaciones, lo que comporta, a su vez, informar, que no adoctrinar, sobre las principales concepciones culturales, morales o ideológicas que, más allá de ese espacio ético común, pueden existir en cada momento histórico dentro de la sociedad y, en aras de la paz social, transmitir a los alumnos la necesidad de respetar las concepciones distintas a las suyas pese a no compartirlas» (STS, Sala 3, de 11 de febrero de 2009 -n. Recurso: 905/2008).

52 Según el TS, en sentencia de 24 de enero de 1985, «el Estado podrá con sus centros docentes públicos dar satisfacción a las máximas exigencias del alumnado y de la enseñanza, considerada como transmisión de conocimientos científicos, pero lo que no puede es suplir la existencia de centros docentes privados con su idea rio educativo propio, donde los padres de familia sientan realizado el derecho fundamental de que sus hijos reciban la formación educativa de acuerdo con sus propias convicciones».

53 Cfr. CELADOR ANGÓN, O.: El derecho de libertad de cátedra, estudio legal y jurisprudencial, Universidad Carlos III-Boletín Oficial del Estado, Madrid 2007; EXPÓSITO, E.: La libertad de cátedra, Tecnos, Madrid 1995; FREIXES SANJUAN, T.: «Los problemas de la libertad de cátedra», en Cuadernos de la Cátedra Fadrique Furio Ceriol, vols. 22/23 (1998), págs. 35-45; LORENZO, P.: «Acerca de la libertad de cátedra», en Derecho y Opinión, vol. 2 (1994), págs. 255-265; LOZANO CUTANDA, B.: La libertad de cátedra, Marcial Pons, Madrid 1995; REGUEIRO, Ma T.: «Libertad de cátedra», en Integrados. Claves jurídicas: derecho a la educación, diversidad religiosa y cohesión social, Ministerio de Justicia, Madrid 2019, págs. 145-164; VIDAL PRADO, C.: La libertad de cátedra: un estudio comparado, CEPC, Madrid 2001.

54 Cfr. CANDO SOMOANO, M. J.: «Algunos aspectos polémicos del derecho a la libertad de cátedra: a propósito de la Sentencia del Tribunal Constitucional 179/1996, de 12 de noviembre», en 
frente al Estado, "cuyo contenido está modulado por las características propias del puesto docente o cátedra cuya ocupación titula para el ejercicio de esa libertad» (STC 5/1981).

Pues bien, teniendo en cuenta el objeto del trabajo, sólo se va a hacer referencia a la libertad de cátedra en centros públicos ${ }^{55}$. En dicho ámbito, la libertad de cátedra adopta un claro concepto y contenido negativos que se concreta en un ámbito de no interferencia o de libertad frente a posibles actos que puedan tener como finalidad $\mathrm{u}$ objetivo el dotar a sus enseñanzas de una orientación ideológica determinada. En este sentido, el TC -en la sentencia tanta veces citada de 1981- ya puso de manifiesto que «en los centros públicos de cualquier grado o nivel, la libertad de cátedra tiene un contenido negativo uniforme en cuanto que habilita al docente para resistir cualquier mandato de dar a su enseñanza una orientación ideológica determinada, es decir, cualquier orientación que implique un determinado enfoque de la realidad natural, bistórica o social dentro de los que el amplio marco de los principios constitucionales hace posible» (FJ 9). En definitiva, el principio de neutralidad que preside a los centros públicos supone e impone a los docentes la prohibición de cualquier forma de adoctrinamiento ideológico de los alumnos ${ }^{56}$. Por tanto, no resulta lícito que los profesores utilizando la función que realizan, garantizada institucionalmente, ejerzan en los centros públicos el adoctrinamiento y el dogmatismo, ya que en la medida de lo posible deben ser neutrales. Amén de resultar necesario respetar la libertad de conciencia de los alumnos, habida cuenta de que «los derechos de los niños y jóvenes, que son los destinatarios directos del ejercicio de esta libertad son un claro límite a la misma» ${ }^{57}$.

Junto a ello, la libertad de cátedra tiene también un contenido positivo, más acentuado en los niveles superiores que en los inferiores donde planes de estudio y especificaciones didácticas inciden en mayor medida sobre la libertad del docente. En este sentido, se ha señalado que «el profesor en la transmisión de sus conocimientos no debe hacer propaganda politica ni adoctrinamiento al alumnado; el profesor debe transmitir al alumno valores y pautas de comportamiento, enfoques sobre el objeto de conocimiento que en muchos casos serán tan lícitos como discutibles, distinguiendo entre lo que puede ser una percepción subjetiva, más o menos discutida, pero respetuosa de lo que sería el adoctrinamiento dogmático y la manipulación de las conciencias» ${ }^{58}$. El profesor deberá, pues, exponer un cuadro completo de la realidad, en el marco de los principios y valores constitucionales, y atendiendo especialmente a la dignidad humana y al derecho al libre desarrollo de la personalidad

Cuadernos Constitucionales de la Cátedra Fadrique Furió Ceriol, vols. 22/23 (1998), págs. 235-247; CASTILLO CÓRDOVA, L.: La libertad de cátedra en una relación laboral con ideario: hacia una interpretación armonizadora de las distintas libertades educativas, Tirant lo Blanch, Valencia 2006.

55 Ver CONTRERAS MAZARÍO, J.M.: «Ideario y derechos educativos en el modelo español», en FERNÁNDEZ-CORONADO, A. (coor.): Integrados..., op. cit., págs. 67-108.

56 STC 5/1981, FJ 9: "Libertad de cátedra es, en este sentido, noción incompatible con la existencia de una ciencia o una doctrina oficiales».

57 SUÁREZ MALAGÓN, R.: «Libertad de cátedra en la enseñanza pública no universitaria», en Revista de Facultad de Derecho de la UNED, 2011, p. 439.

58 FERNÁNDEZ MIRANDA, A., y SÁNCHEZ NAVARRO, A. J.: Enseñanza en Comentarios a la Constitución española de 1978, Edersa, Madrid 1997, p. 243. 
de los alumnos. Podrá dar sus opiniones, pero debe también explicar cuáles son las diversas opciones, y mostrar un interés honesto en la búsqueda de la verdad. Y, por último, podrá hacerlo con mayor intensidad cuanto más elevado sea el nivel educativo en que imparte docencia. En definitiva, y tal y como manifiesta nuestro alto Tribunal, «en un sistema jurídico político basado en el pluralismo, la libertad ideológica y religiosa de los individuos y la aconfesionalidad del Estado, todas las instituciones públicas y muy especialmente los centros docentes, han de ser, en efecto, ideológicamente neutrales. Esta neutralidad, que no impide la organización en los centros públicos de enseñanzas de seguimiento libre para hacer posible el derecho de los padres a elegir para sus hijos la formación religiosa y moral que esté de acuerdo con sus propias convicciones (art. 27.3 de la Constitución), es una característica necesaria de cada uno de los puestos docentes integrados en el centro, y no el bipotético resultado de la casual coincidencia en el mismo centro y frente a los mismos alumnos, de profesores de distinta orientación ideológica cuyas enseñanzas se neutralicen recíprocamente. La neutralidad ideológica de la enseñanza en los centros escolares públicos regulados en la L.O.E.C.E. impone a los docentes que en ellos desempeñan su función una obligación de renuncia a cualquier forma de adoctrinamiento ideológico, que es la única actitud compatible con el respeto a la libertad de las familias que, por decisión libre o forzadas por las circunstancias, no han elegido para sus hijos centros docentes con una orientación ideológica determinada y explícita» (FJ 9 in fine).

\subsection{Currículos educativos y valores constitucionales}

1.- Llegados a este punto, seguidamente debemos abordar la temática relativa a los currículos educativos, tanto desde el plano material como competencial. Desde una perspectiva competencial, debemos señalar que no existe ni puede deducirse del artículo 27 de la CE el establecimiento de un único y completo sistema educativo ${ }^{59}$, sino que su establecimiento queda reservado a los distintos poderes públicos competentes en la materia (esto es, Ministerio de educación; Consejerías de Educación y Consejos escolares). Es a estos y sólo a estos a quienes corresponden el establecimiento del modelo y la fijación de los niveles, las materias, disciplinas, asignaturas y actividades que deben ser cursadas, tal y como se deduce del artículo 27.5 de la $\mathrm{CE}^{60}$.

Mientras que por lo que respecta al ámbito material, debe manifestarse que los contenidos que al efecto se establezcan deberán tener presente los objetivos de la educación; entendidos éstos como un conjunto de principios, garantías y mandatos. Se asigna así a la educación un contenido que puede ser calificado como de “ética»o «moral» en un sentido cívico y aconfesional ${ }^{61}$. Me estoy refiriendo, en concreto, a los objetivos del «pleno desarrollo de la personalidad humana y de su dignidad» enun-

59 STS de 31 de enero de 1997 , párr. 5.

60 Art. 27.5 CE: «Los poderes públicos garantizan el derecho de todos a la educación, mediante una programación general de la enseñanza, con participación efectiva de todos los sectores afectados y la creación de centros docentes».

61 STS de 31 de enero de 1997, párrafo 6. 
ciados en la CE (arts. 10.1 y 27.2) y en el PIDESC (arts. 27.1 y 13.1, respectivamente), así como «el respeto a los principios democráticos de convivencia y a los derechos y libertades fundamentales» (art. 27.2 CE). Contenido todo él que se constituye en «principio rector», «norma directriz» o «cláusula teleológica» de nuestro sistema educativo $^{62}$. Ello implica para los Estados en general, y para España en particular, la obligación de adoptar un sistema educativo basado en la objetividad y la neutralidad (no adoctrinamiento) de sus contenidos ${ }^{63}$, de modo que capacite a todas las personas para participar efectivamente en una sociedad libre, al tiempo que debe favorecer «la comprensión, la tolerancia y la amistad entre todas las naciones y entre todos los grupos raciales, étnicos o religiosos, combatir los prejuicios frente a grupos minoritarios o excluidos socialmente y los estereotipos que conduzcan, justifiquen, inciten o promuevan el odio o la discriminación y promover las actividades conducentes al mantenimiento de la paz» (arts. 13.1 PIDESC, 5.1 CDE [1960] y 4 CDR) ${ }^{64}$.

En consecuencia, los reseñados principios y valores no deben quedarse en papel mojado, sino que deben ser incluidos en los programas, materias y disciplinas, así como impregnar el contenido de los libros de textos, las clases impartidas, los seminarios ofrecidos y todos los medios didácticos posibles que sirvan para educar. Y nada del contenido que forma o puede integrar el apartado 2 , del artículo $27^{65}$, puede ser rechazado ni por los docentes ${ }^{66}$, ni tampoco por los padres ${ }^{67}$ o los propios alumnos, ya

62 Ver art. 2 LOE, modificado por la LOMCE, art. Único.

63 Sobre neutralidad escolar, vid. RUIZ MIGUEL, A.: «Educación para la ciudadanía: entre la neutralidad estatal y la objeción de conciencia», en Anuario de Filosofía del Derecho, vol. 26 (2010), págs. 107-146.

64 A estos efectos, también resulta significativo traer a colación lo manifestado por uno de los Padres de la Constitución (SOLÉ TURA) en el Congreso de los Diputados con motivos del apartado 2, del artículo 27, de la CE: «la educación es formación, y si queremos cumplir lo que dice el artículo 27 en su apartado segundo, la educación debe fomentar los valores de igualdad de oportunidades y de libertad, combatir las discriminaciones y las desigualdades» (SOLÉ TURA, Jordi: «Intervención en el Pleno del Congreso de los Diputados», en Diario de Sesiones del Congreso, núm. 106, de 7 de julio de 1978).

65 Dentro de este contenido no se podrán incluir -según VIDAL PRADO- aquellos contenidos que pongan o puedan suponer una quiebra de la libertad de opinión, la libertad de expresión y de crítica a aquellos aspectos de la Constitución o de las leyes que no se comparten (op. cit., págs. 751-752).

66 Según EMBID, «el profesor, en cuanto que funcionario, está vinculado por un deber o mandato implícito de fidelidad a la Constitución». Aunque reconoce que en aquellas materias relacionadas con el ordenamiento constitucional sería posible formular una crítica técnica a la Constitución, no procedería criticarla cuando no corresponda a la materia de enseñanza. Habla incluso de que el docente debe mostrar una actitud de «fidelidad activa», en el sentido de que el artículo 27.2 obligaría «a la defensa activa de los valores constitucionales», especialmente en los niveles no universitarios, en los cuales los docentes estarían «obligados a imprimir una determinada orientación ideológica a su actividad docente, necesaria para formar a los alumnos en los valores que la Constitución consagra. Esta vinculación positiva a la Constitución constituye un límite a la libertad de cátedra» (EMBID IRUJO, A.: Las libertades en la enseñanza, Tecnos, Madrid 1983, págs. 303-307). Sin embargo, VIDAL PRADO considera que «Lo que debe reclamarse del docente es, simplemente, respeto a la Constitución, pero no una defensa activa de los principios constitucionales, que excedería de lo que le es exigible» (op. cit., pág. 753).

67 El TC ha rechazado un recurso de amparo presentado por unos padres que pretendían practicar la metodología pedagógica del «home schools», sosteniendo que el derecho a la educación, en su dimensión prestacional, «no alcanza a proteger en su condición de derecho de libertad la decisión de los padres de 
que no resulta opinable ni sometido a aceptación o autorización previa, ya sea de los propios poderes públicos ${ }^{68}$ o, como en este caso, de los padres (STC 133/2010, FJ 9) ${ }^{69}$. Ello ha tenido su reflejo a nivel reglamentario, donde se establece que los programas docentes incluyan, entre otros muchos elementos trasversales, cuestiones como la prevención de la violencia de género, contra personas con discapacidad, terrorista o cualquier otra forma de violencia, racismo o xenofobia, o el desarrollo de la igualdad efectiva entre hombres y mujeres ${ }^{70}$. Por nuestra parte, entendemos que sería deseable que todo ese ideario educativo democrático formara parte de una asignatura curricular de carácter obligatorio en todos los niveles educativos.

2.- Íntimamente relacionado con lo expuesto aparece igualmente el tema del currículo de cada nivel educativo $^{71}$, y con él otras dos cuestiones como son, por un lado, su adopción y establecimiento y, por otro, su naturaleza y eficacia. En cuanto a la primera de las cuestiones, esto es, la adopción y establecimiento del sistema educativo, cabe señalar que la organización territorial del Estado incide de una manera directa en la materia educativa ${ }^{72}$, reservando al Estado la competencia exclusiva en la regulación de las condiciones de obtención, expedición y homologación de títulos académicos y profesionales, así como las normas básicas para el desarrollo del artículo

no escolarizar a sus hijos». No obstante, dice también el Alto Tribunal que, si bien en este momento la escolarización es en España obligatoria, «a la vista del artículo 27 CE, no cabe excluir otras opciones legislativas que incorporen una cierta flexibilidad al sistema educativo y, en particular, a la enseñanza básica, sin que ello permita dejar de dar satisfacción a la finalidad que ba de presidir su configuración normativa (art. 27.2 CE) así como a otros de sus elementos ya definidos por la propia Constitución (art. 27.4, 5 y 8 CE)» (STC 133/2010, FJ 9).

68 Es más, para VIDAL PRADO puede tener consecuencias también en los centros docentes concertados: «la libertad de dotar de ideario propio a los centros concertados que pueden recibir fondos públicos, la inclusión dentro del proyecto educativo (o del carácter propio, o ideario) del centro el modelo pedagógico de la educación diferenciada, la implantación de una asignatura específica de Educación para la Ciudadanía con determinados contenidos, etc.» (cit. en VIDAL PRADO, C.: op.cit., pág. 750).

69 A este respecto debemos manifestar que resulta curioso que se reconozca su existencia, incluso el deber constitucional de los poderes públicos en su promoción, y al mismo tiempo se rechacen cuando ese ideario se plasma en el contenido de una asignatura alegando para no recibirlo y reconociendo la existencia de un derecho a la objeción de conciencia. $\mathrm{O}$, como en el presente caso, cuando el mismo queda en el ámbito de los contenidos trasversales, y respecto de determinados contenidos (sobre todo los relacionados con la igualdad de género o con la sexualidad), y su transmisión da lugar a actividades complementarias, aparezca el carácter «voluntario» respecto a las mismas y, por ende, la posibilidad de que los padres se puedan oponer a que sus hijos participen en éstas. Cfr. VÁZQUEZ ALONSO, V.: «La cara y la cruz: ¿Vulnera el 'pin parental' el artículo 27 de la Constitución?», en Actualidad Jurídica Aranzadi, n. 960, 27 de febrero de 2020.

70 Art. 10 RD 126/2014, de 28 de febrero, por el que se establece el currículo básico de la Educación Primaria (BOE núm. 52, de 1 de marzo de 2014) y art. 6 RD 1105/2014, de 26 de diciembre, por el que se establece el currículo básico de la Educación Secundaria Obligatoria y del Bachillerato (BOE núm. 3, de 3 de enero de 2015).

71 Ver art. 6 LOE modificado por la LOMCE.

72 Ver a este respecto, LÓPEZ-GUERRA, L.: «La distribución de competencias entre Estado y Comunidades Autónomas en materia de educación», en Revista Española de Derecho Constitucional, núm. 7 (1983), págs. 293-334; ID.: «Conflictos competenciales, interés general y decisión política», en Revista del Centro de Estudios Constitucionales, n1 (1988), págs. 77-92. 
27 de la CE (art. 149.1.30 CE) ) $^{73}$; al tiempo que los Estatutos de Autonomía vigentes hasta la fecha han asumido competencias plenas en materia de enseñanza, haciendo uso de la cláusula del artículo 148.2 de la Constitución ${ }^{74}$.

Por lo que respecta a los posibles contenidos del artículo 27.2 de la CE, el legislador orgánico los ha concretado en el artículo 2 de la LOE, modificados por la LOMCE (art. único), y garantizados por el artículo 18.1 de la LODE, al establecer que «todos los centros públicos desarrollarán sus actividades con sujeción a los principios constitucionales, garantía de neutralidad ideológica y respeto de las opciones religiosas y morales a que bace referencia el artículo 27.3 de la Constitución». Partiendo de estos principios, el legislador ha establecido las distintas disciplinas curriculares integradas por «asignaturas troncales», «asignaturas específicas» y «asignaturas de libre configuración autonómica» (art. 6 LOE modificado por la LOMCE: art. único) ${ }^{75}$; distribución ésta que no obedece a la importancia o carácter instrumental o fundamental de las asignaturas, sino a la distribución de competencias entre el Estado y las Comunidades Autónomas, acorde con la Constitución española.

Junto a ello, y por lo que al tema objeto de debate se refiere, cabe precisar que, tanto la LODE como la LOE, establecen que las actividades lectivas que se impartan en los centros deben complementarse con otras actividades fuera y dentro del aula y fuera y dentro del horario lectivo, que desarrollen aspectos no incluidos en los currículos (art. $121 \mathrm{LOE}$ ); todo ello enmarcado dentro de los límites del artículo 18 de la $\mathrm{LODE}^{76}$. Sin embargo, su régimen jurídico no resulta tan preciso, toda vez que a nivel legislativo las referencias resultan imprecisas, quedando — como se ha podido observar- su desarrollo normativo en poder de las Comunidades Autónomas. Es más, su concreción queda en manos de los respectivos centros docentes, siendo éstos quienes, en base a su autonomía, pueden organizar este tipo de actividades (art. 121.1 LOE) y quienes deben recogerlas en su programación general anual (art. 125 LOE), al tiempo que son los profesores los, entre sus funciones, la promoción, organización y participación en las mismas (art. 91.1.f) LOE). Por ello, entendemos que sería oportuno

73 Ver art. 6.bis LOE introducido por la LOMCE.

74 Vid., por todos, Estatuto de Autonomía de Andalucía: arts. 21 y 11 en relación con el arts. 52 y 53.

75 Real Decreto 126/2014, de 28 de febrero, por el que se establece el currículo básico de la Educación Primaria (BOE núm. 52, de 1 de marzo de 2014); y Real Decreto 1105/2014, de 26 de diciembre, por el que se establece el currículo básico de la Educación Secundaria Obligatoria y del Bachillerato (BOE núm. 3, de 3 de enero de 2015).

76 Cfr. ÁLVAREZ ÁLVAREZ, L.: «Dilemas jurídicos en la educación en una Europa multicultural: Formar en el pluralismo o en la tradición cultural occidental», en Cuadernos monográficos de teoría del estado, derecho público e historia constitucional, núm. 7 (2012), págs. 393-427; LETURIA NAVAROA, A.: «Educación para la inclusión en un modelo intercultural de gestión de la diversidad», en CASTRO JOVER, A. (Dir.): Interculturalidad y Derecho, Thomson Reuters-Aranzadi, Pamplona 2013; PEREZ ALVAREZ, S.: «La educación intercultural como fundamento del ideario educativo constitucional», en AA.VV.: Integrados..., op. cit., págs. 167-205; VEGA GUTIÉRREZ, A.M.: «Diversidad, religión y cultura en la educación», en VEGA GUTIÉRREZ, A.M. (Coord.): La gestión de la diversidad religiosa en el sistema educativo español, Thomson Reuters-Aranzadi, Pamplona 2014. 
que en una futura modificación de la normativa orgánica sobre educación se delimitara y precisara de una manera más clara el régimen jurídico de este tipo de materias $^{77}$.

Ahora bien, también debe señalarse que ello no impide poner de manifiesto el carácter obligatorio de este tipo de actividades, lo son — como se ha señalado- para los profesores y también para los alumnos (art. 6.4.b) LOE), y así se ha recogido - p.ej.- en la normativa autonómica andaluza, donde se distingue entre actividades complementarias $^{78}$ y actividades extraescolares (art. $1^{\circ}$ Orden de 14 de julio de 1998 [Junta de Andalucía]) ${ }^{79}$; constituyendo las primeras «todas aquellas actividades lectivas desarrolladas por los centros y coherentes con su Proyecto Educativo, por lo que serán evaluables y obligatorias para el alumnado, aunque resulten diferenciadas por el momento, espacio o recursos que se utilizan» (art. 2 Orden 1998) ${ }^{80}$. Mientras que

77 La regulación de estas actividades comienza con la Ley Orgánica 8/1985, de 3 de julio, Reguladora del Derecho a la Educación (LODE), donde en su art. 57, referente a las funciones del Consejo Escolar, establece la promoción y el desarrollo de este tipo de actividades. Dicha norma fue desarrollada por RD 1694/1995, de 20 de octubre, en el que se regulan las actividades escolares complementarias, las actividades extraescolares y los servicios complementarios de los centros concertados. Sin embargo, es en la posterior Ley Orgánica 9/1995, de 20 de noviembre, de la Participación, la Evaluación y el Gobierno de los Centros Docentes, donde se amplía la consideración de las actividades complementarias, definiéndose éstas como las organizadas por el centro escolar de acuerdo con su proyecto educativo y dentro del horario de permanencia en el centro (Disp. Final $1^{\mathrm{a}}$ ). Poco después se aprueban el RD 82/1996, de 26 de enero, por el que se aprueba el Reglamento Orgánico de las Escuela de Educación Infantil y de los Colegios de Educación Primaria y el RD 83/1996, de 26 de enero, por el que se aprueba el Reglamento Orgánica de los Institutos de Educación Secundaria Obligatoria, articulándose el cómo y de qué forma se llevará a cabo la organización y el desarrollo de estas actividades. Así, mientras que para las Escuela de Educación Infantil y Colegios de Educación Primaria las actividades complementarias serán promovidas por el equipo docente (art. 24), en los Centros de Educación Secundaria Obligatoria se establecerán los Departamentos de orientación y de Actividades Complementarias y Extraescolares encargados de la propuesta y desarrollo de este tipo de iniciativas (art. 45). Además, se dota a las Consejerías de Educación y Cultura de competencias propias para la organización y funcionamiento de estos departamentos en los Institutos de Educación Secundaria.

78 «Las actividades complementarias y extraescolares deben considerarse como acciones complementarias que tienen como finalidad primordial propiciar el pleno desarrollo de la personalidad del alumno, a cuyo fin es imprescindible que trasciendan el ámbito puramente académico extendiendo la acción formativa de los alumnos hasta el medio en que el Centro Educativo se halle inserto e incidiendo en sus aspectos económicos, culturales, sociolaborales, etcétera, por lo que no deben enfocarse como actividades imprescindibles para la consecución de los objetivos específicos asignados a las determinadas materias, sino como un complemento de la acción instructiva y formativa de éstas. 》 (VALLINA, 2008)

79 Las Actividades Extraescolares y Complementarias se rigen en Andalucía por la Orden de 14 de julio de 1998, por la que se regulan las actividades complementarias y extraescolares y los servicios prestados por los Centros docentes públicos no universitarios (BOJA núm. 86, de 1 de agosto de 1998). Ver también el Reglamento Orgánico de las Escuelas de Educación Infantil y de los Colegios de Educación Primaria, aprobado por el Decreto 201/1997, de 3 de septiembre, y el Reglamento Orgánico de los Institutos de Educación Secundaria, aprobado por el Decreto 200/1997, de 3 de septiembre, hacen una regulación global de estas actividades en los Centros públicos de enseñanzas de régimen general de nuestra Comunidad Autónoma.

80 Ver a este respecto, art. 2.3 Orden de 1998.

(C) UNED. Revista de Derecho Politico

N. ${ }^{\circ} 110$, enero-abril 2021, págs. 79-112 
las actividades extraescolares son «aquellas que, resultando coherentes con el Proyecto Educativo de Centro y realizadas por éste, no están incluidas en los proyectos curriculares y, por tanto, tienen carácter voluntario para el alumnado, no formando parte de su proceso de evaluación» (art. 3 Orden 1998) ${ }^{81}$. Ello, sin embargo, no es óbice para que respecto de las mismas también se haya incluido el requisito de la voluntariedad (art. $88 \mathrm{LOE}$ ), aunque de una manera imprecisa y, una vez más, poco clara. Una situación que ha permanecido inalterable igualmente tanto a nivel reglamentario $^{82}$ como a nivel autonómico ${ }^{83}$. No obstante, en el caso de la Región de Murcia, los decretos por los que se establecen los currículos prevén que las actividades complementarias «serán evaluables a efectos académicos y obligatorias, tanto para los maestros como para los alumnos», salvo que éstas se realicen fuera del centro o precisen aportación económica por parte de las familias, en cuyo caso serán voluntarias ${ }^{84}$.

81 ANEXO I, Informando a Vicedirección de la actividad a realizar con los siguientes apartados: Denominación de la actividad, objetivo de la actividad, lugar de celebración, características o itinerarios, número de alumnos implicados, cursos implicados, profesores acompañantes, fecha y horario de la actividad, relación de alumnos con circunstancias especiales transporte, etc.

ANEXO II-A, Autorización paterna o del tutor legal para la realización de actividades fuera del municipio y en las que requieran transporte escolar si es menor de edad. (Recogerlo 3 días antes de la actividad).

ANEXO II-B, Para las actividades realizadas en el municipio y cercanías del centro que no requieran transporte se firma una autorización de los padres o tutores válida para todo el curso escolar una vez aprobadas por el Consejo escolar a principio del curso. Por lo tanto, no necesitan el Anexo II-A. No obstante, lo anterior, se informará de todos los detalles antes de llevar a cabo cada una de ellas por si procediera la revocación de la autorización, que tendrá que ser presentada por el padre, madre o tutor con una antelación de 24 horas en el Centro.

ANEXO III, donde se informa a los padres o tutores legales de la actividad a realizar con los siguientes apartados: nombre de la actividad, lugar de celebración, fecha y horario, programa detallado de la actividad, transporte, lugar de encuentro y llegada, actividades a realizar, teléfono de urgencia o contacto con el profesorado y recomendaciones de ropa, útiles o material necesario.

82 Disp. Adic. $7^{a}$ RD 126/2014 y Disp. Adic. 9a RD 1105/2014.

83 Ver, entre otras, Canarias: Orden de 20 de junio de 2007, de la Consejería de Educación, Cultura y Deportes, por la que se regulan las actividades escolares complementarias, actividades extraescolares y servicios escolares en los Centros privados concertados de Canarias: art. 2; Castilla y León: Decreto 7/2017, de 1 de junio, por el que se regulan las actividades escolares complementarias, las actividades extraescolares y los servicios complementarios en los centros concertados en la Comunidad de Castilla y León: art. 8; y Madrid: Resolución de la Dirección General de Innovación, becas y ayudas a la Educación por la que se dictan instrucciones sobre actividades complementarias, extraescolares y servicios escolares complementarios, de aplicación en los centros privados sometidos con fondos públicos de la Comunidad de Madrid: punto 4.3.3.

84 Decreto 198/2014, de 5 de septiembre (art. 25.3.f); Decreto 220/2015, de 2 de septiembre (art. 33.3.e), y Decreto 221/2015, de 2 de septiembre (art. 26.3.e). 


\subsection{Derecho a la objeción de conciencia educativa y «reserva de ley»}

Tras lo expuesto, cabe señalar que lo que, en definitiva, se prevé es que los padres puedan objetar que sus hijos participen, pero no pueden evitar que el centro realice la actividad; por lo que la cuestión entonces es si cabe el reconocimiento del mencionado derecho a objetar. En este caso, al contrario de lo sucedido con la asignatura de «Educación para la ciudadanía» ${ }^{85}$, es que quien reconoce o invoca la objeción no son directamente los padres, sino los poderes públicos (en este caso, el Gobierno de la Región de Murcia). A nuestro juicio, la presente situación nos sigue situando ante un supuesto de objeción ${ }^{86}$, toda vez que la misma supone una excepción a un deber jurídico basado en las creencias o convicciones de los padres, ya que el mismo pretende encontrar su fundamento en el artículo 27.3 de la $\mathrm{CE}^{87}$. Amén de la cuestión relacionada con la normativa (interpositio legislatoris) para su establecimiento.

${ }^{85}$ Las sentencias de los Tribunales Superiores de Justicia superan el número de mil, por lo que su citación aquí resulta imposible: ver dicha jurisprudencia en el portal del Consejo General del Poder Judicial (en internet: http://www.poderjudicial.es/cgpj/es/Poder-Judicial/Tribunal-Supremo/ Jurisprudencia/Jurisprudencia-del-TS/).

TS: sentencias de 11 de febrero, Recurso n. 905/2008; de 11 de febrero de 2009, Recurso n. 948/2008; de 11 de febrero de 2009, Recurso n. 949/2008; de 11 de febrero de 2009, Recurso n. 1013/2008; de 11 de marzo de 2009, Recurso n. 4668/2008; de 11 de mayo de 2009, Recurso 1484/2008; de 17 de septiembre de 2009; 6 de mayo de 2010, Recurso 6268/2009; de 6 de mayo de 2010, Recurso 6202/2009; de 2 de junio de 2011, Recurso n. 457/2010; de 2 de junio de 2011, Recurso n. 3206/2010; de 9 de junio de 2011, Recurso n. 3800/2010; de 9 de junio de 2011, Recurso n. 3802/2010; de 9 de junio de 2011, Recurso n. 3549/2010; de 9 de junio de 2011, Recurso n. 3791/2010; de 9 de junio de 2011, Recurso n. 3723/2010; de 9 de junio de 2011, Recurso n. 3823/2010; de 24 de junio de 2011, Recurso n. 3704/2010; de 24 de junio de 2011, Recurso n. 3798/2010; de 24 de junio de 2011, Recurso n. 505/2010; de 24 de junio de 2011, Recurso n. 3203/2010; de 24 de junio de 2011, Recurso n. 3785/2010; de 24 de junio de 2011, Recurso n. 3632/2010; de 24 de junio de 2011, Recurso n. 3717/2010; de 23 de septiembre de 2011, Recurso n. 3783/2010; de 23 de septiembre de 2011, Recurso n. 3786/2010; de 22 de noviembre de 2011, Recurso n. 5260/2009; de 8 de enero de 2012, Recurso n. 5132/2009; de 17 de enero de 2012, Recurso n. 6019/2009; de 25 de mayo de 2012, Recurso n. 3340/2011, de 13 de junio de 2012, Recurso n. 1913/2010, y de 12 de noviembre de 2012, Recurso n. 6856/2010.

TC: sentencias 28/2014, de 24 de febrero; 41/2014, de 24 de marzo, y 57/2014, de 5 de mayo.

86 Para TERUEL LOZANO, «la cuestión principal es que no estamos ante el pretendido ejercicio de una objeción de conciencia constitucional sino ante supuestos de excepciones u opciones previstas normativamente en relación con un determinado deber jurídico (en este caso, la obligatoriedad de ciertas actividades educativas)», op. cit., p. 3.

87 Sobre la problemática de la asignatura de «educación para la ciudadanía», ver CÁMARA VILLAR, G.: «Educación para la ciudadanía y promoción de los Derechos Humanos», en Temas para el Debate, no 149 (2007), pp. 39-41; CASTRO JOVER, A.: «Los valores de la Democracia y Educación para la ciudadanía», en Anuario de Derechos Eclesiástico del Estado, vol. 24 (2008), págs. 291-312; CELADOR, O., LLAMAZARES, D. y TEJÓN, R.: Educación e ideología, Dykinson, Madrid 2010; EMBID IRUJO, A.: «La educación para la ciudadanía en el sistema educativo español. Reflexiones jurídicas», en Revista Española de Derecho Constitucional, núm. 83 (2008), págs. 11-56; FERNÁNDEZMIRANDA CAMPOAMOR, A.: «Educación para la Ciudadanía. Una perspectiva constitucional», en LÓPEZ CASTILLO, A. (ed.): Educación en valores. Ideología y religión en la escuela pública, Madrid 2007, págs. 153 y sigs.; HUERTA GARICANO, I.: «A vueltas con la asignatura de educación para la 


\subsubsection{Objeción de conciencia escolar}

Respecto de esta temática, y partiendo de que no existe en nuestro ordenamiento un derecho autónomo a la objeción de conciencia (cfr. TC: sentencias 160/1987 y 161/1987, ambas de 27 de octubre; 321/1994, de 28 de noviembre, y autos 71/1993, de 1 de marzo, FJ 3, y 214/1996, de 18 de julio) ${ }^{88}$, la cuestión estriba en si la misma puede encontrar su fundamento material en el derecho a la libertad de conciencia y religiosa (art.16 CE) ${ }^{89}$ o, mejor, en el derecho de los padres reconocido en el artículo 27.3 de la CE. Pues bien, cabe precisar, a este respecto, que el alcance de la cuestión puede ser doble, ya que el pretendido derecho puede proyectarse sobre la existencia misma de una concreta o determinada disciplina, como respecto de sus contenidos $\operatorname{concretos}^{90}$. En el primero de los casos, los padres se opondrán a que sus hijos reciban

ciudadanía», en Revista Española de Derecho Administrativo, nº 146 (2010), págs. 389-415; LLAMAZARES FERNÁNDEZ, D.: Educación para la Ciudadanía democrática y objeción de conciencia, Dykinson, Madrid 2008; LÓPEZ-SIDRO LÓPEZ, A., «La objeción de conciencia a la Educación para la Ciudadanía ante los Tribunales Superiores de Justicia», en Revista General de Derecho Canónico y Derecho Eclesiástico del Estado, n. 17, mayo 2008, pp. 1-25 (en internet: www.iustel.com); MARTí SÁNCHEZ, J.M.: «La «Educación para la Ciudadanía»», en Anuario de Derecho Eclesiástico del Estado, vol. XXIII (2007), págs. 225 y sigs.; NUEVO LÓPEZ, P.: «La introducción de la asignatura «Educación para la ciudadanía» y la concepción constitucional del pluralismo político», en Cuadernos constitucionales de la Cátedra Fadrique Furió Ceriol, núm. 56 (2006), págs. 61-79; PRIETO SANCHÍS, L.: «Educación para la ciudadanía y objeción de conciencia», en Persona y Derecho, vol. 60 (2009), págs. 209-240; RUANO ESPINA, L.: «Objeción de conciencia a la Educación para la Ciudadanía», en Revista General de Derecho Canónico y Derecho Eclesiástico del Estado, ${ }^{\circ} 17$ (mayo 2008), págs. 5 y sigs.

88 En este sentido, ver por todos CASTRO JOVER, A: «La libertad de conciencia y la objeción de conciencia individual en la jurisprudencia constitucional española», en MARTINEZ-TORRÓN, J.: La libertad religiosa y de conciencia ante la justicia constitucional, Ed. Comares, Granada 1998, págs. 133-186. En contra, ver también por todos MARTÍN SÁNCHEZ, I.: «Objeción de conciencia y Educación para la Ciudadanía», en RJUAM, vol. 1, no 19 (2009), págs. 211-228; OLLERO, A.: «Objeción de conciencia y desobediencia civil», en Diario de Derecho, 2005.

89 A nivel general, cabe señalar que el TC tuvo ocasión de pronunciarse esencialmente con relación a dos materias: la prestación del servicio militar (STC 160/1987 y 161/1987), la primera, y la despenalización de la interrupción voluntaria del embarazo (STC 53/1985), la segunda. La posición del Alto Tribunal resulta en principio contradictoria entre sí, toda vez que en el caso del aborto falla a favor de la existencia de un derecho a la objeción de conciencia (cfr. TC: sentencias 15/1982, de 23 de abril, FJ 14; 53/1985, de 11 de abril, FJ 14, y 145/2015, de 25 de junio, FJ 4), mientras que en el supuesto del servicio militar su fallo es que no cabe reconocer un derecho a la objeción de conciencia sobre la base del artículo 16 de la CE (cfr. TC: sentencias 160/1987, FFJJ 3 y 4, y 161/1987, ambas de 27 de octubre, FJ 3). En el primero de los supuestos, el TC argumentó que «la objeción de conciencia forma parte del contenido del derecho fundamental a la libertad ideológica y religiosa garantizado en el artículo 16.1 de la Constitución» (FJ 14); mientras que en el segundo, el mismo Tribunal consideró que «la objeción de conciencia con carácter general, es decir, el derecho a ser eximido del cumplimiento de los deberes constitucionales o legales por resultar ese cumplimiento contrario a las propias convicciones, no está reconocido ni cabe imaginar que lo estuviera en nuestro Derecho o en Derecho alguno, pues significaría la negación misma de la idea de Estado» (FJ 3).

90 Cfr. ARECES PIÑOL, $M^{\text {a }}$ T.: «Derecho a objetar en el ámbito educativo: educación para la ciudadanía. Resoluciones Judiciales», en Anuario de Derecho Eclesiástico del Estado, vol. 25 (2009), págs. 343-377. 
una determinada disciplina o enseñanza por ser o resultar contraria a sus convicciones o creencias $^{91}$. Mientras que, en el segundo de los supuestos, lo que los padres alegan es que en los mismos o con los mismos se está lesionando lo previsto en la Constitución $^{92}$, y con ello su negativa u «objeción» a dichos contenidos, dado su carácter «ideológico» ${ }^{93}$; siendo ésta y no otra la justificación o fundamento que subyace en el llamado «pin parental».

Respecto del posible conflicto entre los apartados 2 y 3 del artículo 27, así como su relación con el artículo 16.1 de la CE, el TS ha considerado que los mismos se limitan mutuamente. En concreto, precisa que «(...) el Estado no puede llevar sus competencias educativas tan lejos que invada el derecho de los padres a decidir sobre la educación religiosa y moral de los hijos; pero, paralelamente, tampoco los padres pueden llevar éste último derecho tan lejos que desvirtúe el deber del Estado de garantizar una educación «en el respeto a los principios democráticos de convivencia y a los derechos y libertades fundamentales»» (FJ 9). Ahora bien, a tales efectos diferencia entre los valores que constituyen el sustrato moral del sistema constitucional —contenidos en normas jurídicas vinculantes y representados sobre todo por los derechos fundamentales-y la explicación del pluralismo existente en la sociedad en sus diversas manifestaciones. En relación con los primeros, considera que es constitucionalmente lícita su promoción para suscitar la adhesión a ellos, por lo que no cabe hablar aquí de adoctrinamiento ${ }^{94}$; mientras que, respecto del segundo, señala que los poderes públicos deben exponerlo de una manera rigurosamente objetiva, pues la neutralidad estatal permite en este punto informar, pero no adoctrinar ${ }^{95}$. Por tanto, tampoco esta enseñanza de la diversidad — cultural, moral o ideológica - existente en la sociedad se opone al derecho de los padres a elegir

91 Es el caso que sucede, por ejemplo, cuando algunos padres musulmanes se han negado a que sus hijas reciban o asistan a las clases de música o de gimnasia.

92 En este sentido, el TS después de afirmar que la Educación para la Ciudadanía es ajustada a Derecho y que el deber jurídico de cursarla es válido, insiste en que ello «no autoriza a la Administración educativa — ni tampoco a los centros docentes, ni a los concretos profesores - a imponer o inculcar, ni siquiera de manera indirecta, puntos de vista determinados sobre cuestiones morales que en la sociedad española son controvertidas» (Sentencias de 11 de febrero de 2009, Recurso n. 905/2008, FJ 10; 11 de febrero de 2009, Recurso n. 948/2008, FJ 15; 11 de febrero de 2009, Recurso n. 949/2008, FJ 15; 11 de febrero de 2009, Recurso n. 1013/2008, FJ 15; y 11 de marzo de 2009, Recurso n. 4668/2008, FJ 9).

93 Con relación a esta temática, ver TEDH: sentencias de 23 julio de 1968, caso Aspectos de los derechos en el uso de las lenguas en la educación en Bélgica c. Bélgica; de 7 de diciembre de 1976, caso Kjeldsen, Busk Madsen y Pedersen c. Dinamarca; de 25 de febrero de 1982, caso Campbell y Cosans c. Reino Unido; de 25 de mayo de 2000, caso Jiménez Alonso y Jiménez Merino c. España; de 29 de junio de 2007, caso Folguera y otros c. Noruega; de 9 de octubre de 2007. Caso Hasan y Eylem Zengrin c. Turquía; de 15 de junio de 2010, caso Grzelak c. Polonia; de 18 de marzo de 2011, caso Lautsi y otros c. Italia, y de 13 de septiembre de 2011, caso Dojan y otros c. Alemania.

94 TS: TS: sentencias de 11 de febrero de 2009, Recurso n. 905/2008, FJ 6; 11 de febrero de 2009, Recurso n. 948/2008, FJ 6; 11 de febrero de 2009, Recurso n. 949/2008, FJ 6; 11 de febrero de 2009, Recurso n. 1013/2008, FJ 6; y 11 de marzo de 2009, Recurso n. 4668, FJ 5.

95 En concreto, el Tribunal Supremo señala que «la enseñanza del pluralismo existente en la sociedad no es incompatible con el derecho a la libertad ideológica y religiosa, garantizado en el artículo 16.1 de la Constitución, siempre que su exposición se haga con neutralidad y sin adoctrinamiento» (FJ 7). 
la orientación moral y religiosa que desean para sus hijos (art. 27.3 CE), siempre que la misma se realice de una manera objetiva, crítica y plural que permita a los alumnos desarrollar su sentido crítico, huyendo de este modo de toda finalidad de adoctrinamiento ${ }^{96}$.

Para el Tribunal Supremo, los argumentos que acabamos de mencionar serían suficientes para considerar ajustada a Derecho la asignatura de «Educación para la Ciudadanía» ${ }^{97}$; no obstante, aborda también la existencia o no de un pretendido derecho a la objeción de conciencia, afirmando que no existe un derecho constitucional general a la objeción de conciencia, ni siquiera como proyección del artículo 16 de la Constitución, porque éste encuentra su límite en la Ley ${ }^{98}$. Por lo cual, el Tribunal — como ya hiciera en su momento el $\mathrm{TC}^{99}$ — opone a la objeción de conciencia el artículo 9.1 de la Constitución y afirma que «lo contrario supondría hacer depender las normas de su conformidad a cada conciencia individual. Sólo la objeción de conciencia a la prestación del servicio militar se reconoce en la Constitución, de forma que, cualquier otro reconocimiento dependerá de la estricta voluntad del legislador» $(\mathrm{FJ} 8)^{100}$. De esta manera la

96 En este sentido, el TEDH, en el caso Kjeldsen, Busk Madsen y Pedersen c. Dinamarca, ha considerado que «la legislación impugnada no constituye un intento de adoctrinamiento tendente a preconizar un comportamiento sexual determinado, porque no se ocupa de exaltar el sexo ni a incitar a los alumnos a dedicarse precozmente a prácticas peligrosas para su equilibrio, su salud o su futuro, o reprensibles para muchos padres» (párr. 54), toda vez que "la legislación no afecta al derecho de los padres a aconsejar a sus hijos sobre estas cuestiones, ni les impide ejercer sus funciones de educadores ni orientarles en la dirección de sus propias convicciones religiosas o filosóficas» (ibid). Mientras que respecto a la posibilidad de dispensar a los alumnos de ciertas enseñanzas sobre la base de la vulneración del principio de igualdad (art. 2 del PA1CEDH y 14 CEDH), el Tribunal concluye desestimando tal pretensión, al considerar que, «en el campo de los derechos y libertades garantizados por el artículo 14 del CEDH, se probíbe un trato discriminatorio que tenga como razón de ser una característica personal ( «situación») mediante la cual personas o grupos de personas se diferencien unos de otros, sin que se haya demostrado que dicho trato se proporcione en la normativa impugnada debido a la diferente naturaleza que existe entre la educación religiosa y la educación sexual» (párr. 54). Ver también sentencias del TEDH en el caso Folgero c. Noruega, de 20/29 de junio de 2007, y en el caso Hasan Zengin c. Turquía, de 9 de octubre de 2007.

97 El Tribunal Supremo considera asimismo incorrecto sostener que «el Estado no tenga nada que decir sobre la educación de los menores, ni quepa ninguna transmisión de valores a través del sistema educativo» (FJ 7).

98 TS: sentencias de 11 de febrero de 2009, Recurso n. 905/2008, FJ 8; y de 11 de marzo de 2009, Recurso n. 4668/2008, FJ 7.

99 SSTC 160/1987 y 161/1987 y STS de 11 de febrero de 2009, Rec. 905/2008, FJ 8.

100 Para un estudio en profundidad de esta las sentencias del TS, vid. ALÁEZ CORRAL, B.: «Ideario educativo constitucional y respeto a las convicciones morales de los padres: a propósito de las sentencias del tribunal supremo sobre «educación para la ciudadanía»», en El Cronista del Estado social $y$ democrático de Derecho, no 5 (2009), págs. 24-33; ANSUATEGUI, F.J.: «Educación en valores, democracia y objeción de conciencia», en Libertad ideológica y objeción de conciencia: pluralismo y valores en Derecho y educación, Dykinson, Madrid 2011, págs. 145-162; ELÓSEGUI ITXASO, Ma ${ }^{a}$ : «Aconfesionalidad, laicidad y moral privada en la asignatura de Educación para la Ciudadanía y los Derechos humanos», en Cuadernos de Derecho Judicial, I-2008, op. cit., págs. 269-320; GOMEZ ORFANEL, G.: «Jurisprudencia española sobre educación para la ciudadanía», en Anuario de Derechos Humanos. Nueva Época vol. 10 (2009) págs. 261-283. 
cuestión de la interpositio legislatoris adquiere una importancia relevante a efectos de la licitud de la medida adoptada como es la del «pin parental»; cuestión ésta que será abordada en el punto siguiente.

Dentro de este ámbito material, se podría finalmente argumentar que todo lo dicho afecta a disciplinas ordinarias, mientras que en el caso que nos ocupa —el «pin parental»— se trata de actividades complementarias ${ }^{101}$. Pues bien, como suele ocurrir tampoco esto es nuevo ni exclusivo de España. En la sentencia Dojan y otros c. Alemania, los padres de 5 familias pertenecientes a la Iglesia Cristiana Evangélica Baptista solicitan la exención para que sus hijos no asistan a las clases de sexualidad que debían recibir sus hijos en una escuela pública de primaria en Salzkotten (Renania del Norte-Westfalia), así como tampoco a un taller de teatro sobre el cuerpo humano ni su asistencia a un carnaval. En concreto, y por lo que se refiere a la clase de sexualidad y el taller de teatro, los padres alegan que no se oponen a la educación sexual en la escuela como tal, sino que discrepan del contenido de las clases, así como de las actividades y contenidos que se desarrollan en el taller, porque entienden que ambas actividades promueven exclusivamente una visión «liberal» de la sexualidad que implica el adoctrinamiento de sus hijos, al tiempo que discrepan igualmente sobre el contenido del libro que se usaba en estas clases considerándolo, en parte, pornográfico y contrario a la ética cristiana que ellos profesan. Y, finalmente, respecto a la asistencia al carnaval, sostienen que el mismo versa sobre una práctica contraria a sus convicciones religiosas. Por todo ello, entienden que la denegación de la exención constituye una restricción desproporcionada de su derecho a educarles conforme a sus convicciones religiosas y el derecho a que sus hijos reciban una educación correspondiente a sus propias convicciones, derechos todos ellos recogidos en los artículos 8, 9 y 10 CEDH y 2 del PA1CEDH. Sin embargo, el TEDH falla en contra de las pretensiones de los padres al entender que ni la asignatura ni el taller ni el desfile de carnaval pueden entenderse como una forma de adoctrinamiento, y por lo tanto, sus hijos no tienen por qué ser eximidos ${ }^{102}$. Por consiguiente, y a la luz de las anteriores consideraciones, el Tribunal de Estrasburgo estimó que al negarse la exención de las clases de educación sexual obligatoria, el taller de teatro y la asistencia a la fiesta de carnaval, las autoridades nacionales no habían excedido el margen de apreciación que se les concede en el ámbito del artículo 2 del PA1CEDH, sin que — además — se desprendiera prueba alguna que permitiera presumir que la información y los conocimientos impartidos no se desarrollaron de una manera imparcial, crítica y plural $^{103}$.

101 Cfr. VEGA GUTIÉRREZ, A. Mª «Objeciones de conciencia y libertades educativas: los conflictos de conciencia ocasionados por determinados contenidos curriculares», en ROCA, M ${ }^{a} \mathrm{~J}$. (Coord.): Opciones de conciencia. Propuestas para una ley, op. cit., págs. 372 y sigs.

102 Dojan y otros c. Alemania, § 2.

103 Ibid. 


\subsection{2.- Establecimiento «en» una «ley»}

Tras lo expuesto, cabe señalar que la cuestión básica es entonces determinar si no existiendo dicha posibilidad constitucional a favor de los padres, la misma puede existir en favor del poder público (del legislador), esto es, que sea él quien reconozca normativamente dicha posibilidad. Como se ha manifestado con anterioridad, para el reconocimiento de un derecho a la objeción de conciencia resulta necesaria una interpositio legislatoris o, lo que es lo mismo, su reconocimiento depende de la estricta voluntad del legislador, entendido éste en sentido amplio. Por tanto, desde un plano teórico la respuesta no puede ser otra que afirmativa, pero para ello debemos preguntarnos si vale cualquier tipo de norma.

Esta última cuestión tiene, pues, que ver con el instrumento de incorporación al ordenamiento jurídico, o lo que es lo mismo si se puede o no exigir la existencia de una reserva de ley (art. 53.1 CE). A este respecto, debemos manifestarnos a favor de que este tipo de actuaciones aparezcan establecidas y reconocidas en un norma con rango legal, amén de por una cuestión de seguridad jurídica (art. 9.1 CE), porque estamos ante el ejercicio de derechos fundamentales. No obstante, se podría entender que las presentes actividades no forman parte del contenido esencial del derecho fundamental en cuestión, y, por ende, no tendría por qué aplicarse dicha reserva de ley.

Un segundo supuesto podría llevar a entender que nos encontramos ante una dispensa o excepción y, por tanto, de alguna manera ante un límite, pues bien en este caso - y como ha puesto de manifiesto el TEDH — cualquier límite a un derecho fundamental debe estar «establecido por ley» ${ }^{104}$ e igual exigencia se requiere para el reconocimiento de la objeción de conciencia: interpositio legislatoris (cfr. art. 10 CDFUE) ${ }^{105}$. En este sentido, y aunque dicha expresión no tenga que ser interpretada en un sentido literal ${ }^{106}$, lo que amplia sin duda la capacidad de actuación de los poderes públicos ${ }^{107}$, y en este caso de las Comunidades Autónomas, si cabe plantear es el rango de la norma, y en concreto si el instrumento normativo utilizado por el Gobierno de Murcia resulta

104 La exigencia de que toda limitación a un derecho fundamental aparezca cubierta por una ley resulta de las reservas de ley que el CEDH contiene en los artículos 2.1 y 2.2.c; 5.1 y 5.3; 6.1; 8.2; 9.2; 10.2; 11.2 CEDH; y 1.1 y 2 del Protocolo núm. 1; 2.3 y 2.4 del Protocolo núm. 4; 2 del Protocolo núm. $6 ;$ y 2.1 y 2.2, 3, 4.1 y 4.2 del Protocolo núm. 7.

105 El único supuesto reconocido es en el caso del aborto o conectado con él: SSTC 15/1982, de 23 de abril; 53/1985, de 11 de abril, y 145/2015, de 25 de junio; y en la LO 2/2010, de 3 de marzo, de salud sexual y reproductiva y de la interrupción voluntaria del embarazo.

106 Véase a este respecto, entre otras muchas, TEDH: sentencias de 27 de octubre de 1983 (Malone), § 67; de 26 de abril de 1979 (Sunday Times), § 47; de 25 de marzo de 1983 (Silver y otros), § 86; de 25 de marzo de 1985 (Bartbold c. Alemania), § 46; de 24 de noviembre de 1986 (Gillow), § 51; de 24 de marzo de 1988 (OIsson), § 62; de 24 de mayo de 1988 (Müller y otros), § 29; de 28 de marzo de 1990 (Groppera Radio y otros), § 68; de 24 de abril de 1990 (Krusiin y Huvig), § 29; de 22 de mayo de 1990 (Autronic AG), §57; y de 29 de octubre de 1992 (Open Door y Dublin Well Woman), §§ 59-60.

107 Cfr. MARTÍN-RETORTILLO BAQUER, L.: «La calidad de la ley según la jurisprudencia del Tribunal Europeo de Derechos Humanos (especial referencia a los casos «Valenzuela Contreras» y «Prado Bugallo», ambos contra España)», en Derecho Privado y Constitución, núm. 17 (2003), págs. 377-406. 
el adecuado en el establecimiento de este tipo de requisitos respecto de disciplinas que podemos calificar como de «complementarias». En el supuesto analizado, cabe señalar que el requisito se contiene en una «resolución», lo que — a nuestro juicio- no resulta el instrumento normativo más adecuado, toda vez que este tipo de normas tienen una eficacia relativa y un alcance temporal concreto, motivo por el cual el TS de Justicia de esa Comunidad Autónoma ha decretado el archivo del recurso presentado por el Ministerio de Educación contra la citada resolución por «pérdida sobrevenida de objeto» ${ }^{108}$; dando lugar con todo ello a un caso claro de inseguridad jurídica, que no resulta lo más adecuado en el ámbito de la educación y la enseñanza ${ }^{109}$.

\section{CONSIDERACIONES FINALES}

Después de lo expuesto, cabe realizar un conjunto de consideraciones finales, a saber:

— La primera de las consideraciones que debe realizarse tiene que ver con el precepto constitucional que está en el origen de la polémica y que no es otro que el artículo 27, el cual es fruto de dos posiciones contrapuestas y que se manifiestan en la garantía de dos derechos fundamentales como son la educación y la enseñanza, aunque ambos proyectados sobre una única y misma realidad (STC 5/1981). Junto a estos derechos, se manifiestan asimismo otros derechos como son la libertad ideológica y religiosa (art. 16.1), por un lado, y la libertad de cátedra (art. 201.c CE), por otro. La proyección de la libertad ideológica y religiosa sobre la libertad de enseñanza tiene como consecuencia una doble proyección como es, por un lado, la pluralidad de escuelas y la pluralidad en la escuela, salvaguardando de este modo el derecho a la libre formación de la conciencia y el pleno y libre el desarrollo de la personalidad (art. 27.2), así como — por otro— la garantía del derecho de los padres a que sus hijos reciban una formación religiosa y moral de conformidad con sus propias convicciones (art. 27.3).

108 Comunicado del TS de Justicia de Murcia de agosto de 2020. El presente Tribunal con antelación había suspendido la medida de forma cautelar porque consideró que podía tratarse de un «perjuicio identificable» la posibilidad de que algunos alumnos no puedan realizar una actividad obligatoria y evaluable «por no autorizarlo sus padres».

109 De hecho, dicha Comunidad no ha incorporado, en las instrucciones para el curso 2020-2021, referencia alguna a la presente temática: vid. Resoluciones de 22 de julio de 2020, de la Dirección General Evaluación Educativa y Formación Profesional, Dirección General de Planificación Educativa y Recursos Humanos, Dirección General de Centros Educativos e Infraestructuras, y Dirección General de Innovación Educativa y Atención a la Diversidad de la Consejería de Educación y Cultura por la que se dictan instrucciones de comienzo del curso 2020-2021, para los centros docentes que imparten Educación Infantil y Primaria (en internet: https://www.carm.es/web/pagina?IDCONTENIDO= $158107 \&$ IDTIPO $=60 \&$ RASTRO $=\mathrm{c} 1655 \$$ m9563) y para los centros docentes que imparten Educación Secundaria Obligatoria y Bachillerato (en internet: https://www.carm.es/web/ pagina? IDCONTENIDO $=158108 \& I D T I P O=60 \&$ RASTRO $=c 1655 \$ \mathrm{~m} 9563)$, respectivamente 
— En segundo lugar, y partiendo de la consideración de que no existe una prelación de derechos y libertades, se debe buscar un equilibrio entre todos los derechos y libertades en juego, esto es, artículos 16, 20 y 27 de la CE. A este respecto, debe traerse asimismo a colación el artículo 53 de la CE según el cual los distintos poderes públicos están obligados a salvaguardar en todo momento el contenido esencial de estos derechos y libertades, sin que el ejercicio de uno suponga la desaparición total de otro, lo que resultaría contrario a la Constitución.

- Una tercera consideración tiene su objeto en el alcance del derecho garantizado en el apartado 3, del artículo 27, y que supone, por un lado, que los padres puedan elegir entre diversos tipos educativos, obligando a la existencia tanto de centros docentes públicos como privados, y dentro de éstos últimos a que los mismo puedan establecer un carácter o ideario propio ideológicamente caracterizado; y, por otro, el no adoctrinamiento en los centros docentes públicos (SSTC 5/1981 y 77/1985), así como del derecho reconocido a éstos de participar en el control y gestión de todos los centros sostenidos por la Administración con fondos públicos (art. 27.7 CE). Por consiguiente, dicho contenido no supone una facultad en favor de los padres para que éstos puedan oponerse a que sus hijos reciban una determinada enseñanza, asistan a una concreta asignatura o se ausenten de determinadas clases o contenidos (STEDH Dojan y otros c. Alemania).

— Sin olvidar, además, que el presente supuesto —y formaría la cuarta consideración - debe quedar circunscrito —en el caso de que sea reconocido legalmente- al ámbito en los que los menores no tengan madurez suficiente para tomar sus propias decisiones (esto es, Enseñanza Primaria y, todo lo más, $1^{\circ}$ y $2^{\circ}$ de la ESO), ya que si el menor tiene dicha madurez será a éste a quien corresponda, en todo caso, la toma de dicha decisión.

- La quinta de las consideraciones tiene que ver con el establecimiento en nuestra Carta Magna del principio de laicidad positiva (STC 46/2000), lo que en el ámbito de la educación supone la ausencia de una ciencia o doctrina oficiales o, lo que es lo mismo, una instrucción no orientada ideológicamente por los poderes públicos (STC 5/1981). Ello, sin embargo, no supone la no intervención de las autoridades educativas en el establecimiento del correspondiente modelo educativo (art. 27.5 y 8).

- A estos efectos, y partiendo de lo manifestado, cabe afirmar — y sería la sexta de las consideraciones - la no existencia de un derecho general a la objeción de conciencia basado en el artículo 16.1 de la Constitución, y por tanto tampoco cabe la garantía de un derecho de tales características en el ámbito educativo, en esta ocasión con un pretendido amparo, además, del artículo 27.3 de la CE. Nos mostramos en este caso de acuerdo con lo manifestado 
por el TS cuando precisa que «la Constitución no permite afirmar la existencia de un derecho a la objeción de conciencia con carácter general, debiendo ser reconocido para su ejercicio por el legislador en supuestos concretos» (Sentencia de 11 de febrero de 2009, Recurso n. 905/2008, FJ 8) ${ }^{110}$.

- Por ende, para el reconocimiento — y esta sería la séptima y última de las consideraciones - de la presente excepción o dispensa de un deber jurídico válido, deberá existir necesariamente una interpositio legislatoris (cfr. STS de 11 de febrero de 2009, Recurso n. 905/2008, FJ 8). Ahora bien, ello no puede producirse a través de cualquier tipo de norma (como en el caso de la Región de Murcia: una instrucción o resolución), sino que resulta preciso garantizar la seguridad jurídica prevista en el art. 9.1 de la CE, y para ello la mejor manera — al menos a nuestro juicio — es que se realizara a través de una norma con rango legal.

110 En contra, ver el voto particular del Magistrado Don Manuel Campos Sánchez-Bordona a la sentencia de 11 de febrero de 2009, Recurso n. 905/2008; en el número primero de su voto, el Magistrado manifiesta: «Es cierto que parte de la doctrina sentada en las últimas sentencias constitucionales 160 y 161/1987 (...) puede interpretarse en la línea de que sólo el explícito reconocimiento legislativo permitiría el ejercicio singular de la objeción de conciencia (...). Abora bien aquellas sentencias no han llegado a considerar superada la tesis plasmada en la sentencia constitucional 53/1985 (y en la 154/2002) ni creo que a partir de ellas pueda afirmarse que la admisión extralegislativa de la objeción de conciencia reconocida en 1985 deba estimarse errónea o sobrepasada». En el mismo sentido, el voto particular del Magistrado Don Juan José González Rivas a la sentencia de 11 de febrero de 2009, Recurso n. 905/2008, n. VII. 
Title:

Educational values, constitutional ideary and parent's right: the question of «pin or parental censorship»

\title{
Summary:
}

1.- Introduction. 2.- Secularism of the State. 3.- Right to education, freedom of education and constitutional ideology. 3.1. Educational system and guiding principles. 3.2. Parents' right to the moral and religious formation of their children (art. 27.3 CE). 3.3. The child as the holder of educational rights and freedoms. 4.- Educational system, educational curriculums and parental involvement. 4.1. Educational curriculums. 4.2. Public-secular school and conscientious objection. 4.3. Freedom academic. 5.- Final considerations.

\section{Resumen:}

Hablar del llamado «pin parental» es abordar una de las cuestiones de mayor actualidad en España, como lo demuestra que el Ministerio de Educación haya presentado una demanda ante el Tribunal Superior de Justicia de Murcia contra la Instrucción por la que se establece. En la presente cuestión confluyen no sólo las dos visiones que sobre educación y enseñanza se han dado a lo largo de nuestra historia, tanto presente como remota (lo que ya haría relevante la cuestión), y para su justificación se han utilizado dos argumentos, a saber: el derecho de los padres a elegir la formación moral y religiosa de sus hijos, recogida en el apartado 3, del artículo 27, de la CE, el primero, y la propia libertad, el segundo. Pues bien, en el presente trabajo se va a analizar si los mismos resultan o no suficientes, así como buscar un equilibrio entre los derechos de los padres y el contenido de los curricula educativos.

\begin{abstract}
:
To speak of the so-called «parental pin» is to address one of the most current issues in Spain, as evidenced by the Ministry of Education having filed a complaint with the Tribunal Superior de Justicia de Murcia against the Instruction for which it is established. This issue brings together not only the two visions that have been given on education and teaching throughout our history, both present and remote (which would already make the issue relevant), and for its justification two arguments have been used, namely: the right of parents to choose the moral and religious formation of their children, as set out in paragraph 3 of Article 27 of the EC, the first, and their own freedom, the second. In this work, it will be examined whether or not they are sufficient, as well as seeking a balance between the rights of parents and the content of the educational curricula.
\end{abstract}




\section{Palabras clave:}

Educación; enseñanza; derechos de los padres; objeción de conciencia; libertad de cátedra

\section{Key words:}

Education; teachings; parental rights; conscientious objection; academic freedom 
